Swarthmore College

Works

Fall 2020

\title{
The Effects Of Medicare Payment Changes On Nursing Home Staffing
}

Daifeng $\mathrm{He}$

Swarthmore College, dhe1@swarthmore.edu

P. McHenry

J. M. Mellor

Follow this and additional works at: https://works.swarthmore.edu/fac-economics

Part of the Economics Commons

Let us know how access to these works benefits you

\section{Recommended Citation}

Daifeng He, P. McHenry, and J. M. Mellor. (2020). "The Effects Of Medicare Payment Changes On Nursing Home Staffing". American Journal Of Health Economics. Volume 6, Issue 4. 411-443. DOI: 10.1086/ 710563

https://works.swarthmore.edu/fac-economics/505

This work is brought to you for free by Swarthmore College Libraries' Works. It has been accepted for inclusion in Economics Faculty Works by an authorized administrator of Works. For more information, please contact myworks@swarthmore.edu. 


\title{
THE EFFECTS OF MEDICARE PAYMENT CHANGES ON NURSING HOME STAFFING
}

\author{
D A I F E N G H E \\ P E T E R M C H E N Y \\ JEN N F ER M. MELLOR
}

\begin{abstract}
In light of persistent shortcomings in nursing home care quality and evidence that lower nurse staffing levels could be harmful to residents, we examine whether staffing levels are affected by changes in Medicare reimbursement rates. We exploit a 2006 change in Medicare's methodology for adjusting provider payments for geographic differences in costs, a change that generated plausibly exogenous variation in nursing facility reimbursement rates. Our method compares facilities with higher and lower shares of Medicare resident days, which were differentially exposed to the payment changes we examine. Using panel data on US nursing homes from 2003 through 2009, we find that higher Medicare payments increased nurse staffing hours per resident day. Additional results suggest that changes in Medicare payments did not affect other measures of quality.
\end{abstract}

KEYWORDS: Medicare payment reform, nursing home staffing, skilled nursing facility prospective payment system, hospital wage index, geographic realignment JEL CLASSIFICATION: H5, I11, I13, I18

\section{Introduction}

The quality of nursing home care in the United States has been a long-standing concern, as evidenced by numerous academic studies and government reports (e.g., Institute of Medicine 1986, 1996; Mor et al. 2009). In the past 20 years, for example, the US Government Accountability Office has issued more than 20 reports on shortcomings in either nursing home care or the government oversight of nursing homes (US Government Accountability Office 2018). A 2014 report, for example, finds that one-third of short-stay nursing facility residents experience adverse events or harms such as medication errors, delays in receiving necessary care, and dehydration, and that half of these events are preventable (US Department of Health and Human Services Office of Inspector General 2014). Nursing home quality is especially important in the Medicare and Medicaid programs, which together finance nearly 60 percent of US spending on nursing facility care, for a total of $\$ 87.9$ billion in 2017 (Centers for Medicare and Medicaid Services 2018a). One important dimension of nursing facility quality is the level of nursing staff, and a large body of research shows that higher nursing staff levels are associated with reduced cases of infection, dehydration,

Daifeng He (corresponding author, dhe1@swarthmore.edu), Swarthmore College. Peter McHenry and Jennifer M. Mellor, College of William and Mary.

Electronically published September 22, 2020.

American Journal of Health Economics, volume 6, number 4, fall 2020.

(c) 2020 American Society of Health Economists. DOI: 10.1086/710563 
weight loss, and pressure sores; lower mortality; and improvements in physical functioning (e.g., Bostick et al. 2006; Castle 2008; and Dellefield et al. 2015). Additionally, research using instrumental variables methods finds that nursing staff levels have a causal effect on other measures of facility quality (Lin 2014).

While nursing staff levels can be directly impacted by regulations such as minimum staffing requirements, they may also be indirectly impacted by administratively set reimbursement rates in public insurance programs. However, identifying the causal effect of Medicaid or Medicare reimbursement on nurse staffing is a challenge. In the Medicaid program, where reimbursement rates are set by states, rate increases may be a response to increased minimum staffing requirements or higher facility staffing costs. A similar concern pertains to studies examining Medicare payment rates, since differences in Medicare payment rates across areas reflect differences in operating costs (i.e., local area wage differences), which themselves affect staffing levels. Some studies have examined changes in staffing following Medicare's adoption of a prospective payment system (PPS) for skilled nursing facilities (SNFs) in 1998 (e.g., Konetzka et al. 2004), but the SNF PPS changed the payment methodology, not just the payment levels, making it hard to identify the effect of reimbursement rates on staffing.

Our study adds to this literature by using a novel strategy to identify the causal effects of facility-specific Medicare payment changes on nursing home staffing. Specifically, we examine a one-time plausibly exogenous change in the hospital wage index (HWI), an arealevel adjustment to SNF payments. Prior to fiscal year 2006, SNF payments were adjusted by a hospital wage index defined for local areas using metropolitan statistical areas or MSAs; from October 2005 on, the wage index was defined for areas using core-based statistical areas or CBSAs (Centers for Medicare and Medicaid Services 2016; Medicare Prospective Payment System and Consolidated Billing for Skilled Nursing Facilities 2007). As a result, the HWI changed for more than 8,500 nursing facilities nationwide; for 8 percent of facilities, those changes exceeded 3 percentage points. The HWI changes translated to increases or decreases in the per diem Medicare SNF payment rates, and, unlike most other year-to-year changes in the HWI, they provide an important source of payment variation that is unrelated to facility decisions or market factors. We use this quasi-experiment to examine the causal effects of Medicare payment changes on registered nurse (RN) hours per resident day, licensed practical nurse (LPN) hours per resident day, and total direct care staff hours per resident day. Our methodology also compares facilities with higher and lower shares of Medicare resident days, which were differentially exposed to the payment adjustments.

We find that increases in Medicare payments increased staffing hours per resident day at facilities. In particular, a 5 percent increase in Medicare payments increased RN hours per resident day by 9.01 percent (and LPN hours per resident day by 3.24 percent) in facilities with 10 percent of resident days paid by Medicare relative to facilities with no Medicare patients. We find no evidence that changes in Medicare payments affected other measurable dimensions of nursing home quality. Our findings are important given long-standing concerns about nursing home quality and the more recent attention on staffing deficiencies in particular. Moreover, our findings have implications for policies that changed real Medicare payments to nursing facilities as part of the Affordable Care Act (ACA) as well as 
for payment policy recommendations from the Medicare Payment Advisory Commission (MedPAC).

\section{Background and Literature Review}

Both Medicare and Medicaid pay for a significant share of all nursing home care. According to 2016 data, Medicaid covers the cost for 62 percent of all nursing home residents while Medicare is the primary payer for another 14 percent (Kaiser Family Foundation, n.d.). Medicare covers short-term SNF stays following Part A covered inpatient hospitalizations of three days or more; residents covered by Medicare receive skilled nursing services, which are services ordered by physicians and provided by RNs, LPNs, or physical therapists. Medicaid typically covers longer-term stays for residents needing custodial care and assistance with activities of daily living, such as dressing, bathing, and toileting. Medicaid reimbursement policies are determined by individual states subject to federal rules. Medicare reimbursement follows federal guidelines under the SNF PPS.

Only a few prior studies have examined the effects of Medicare payment changes on nursing home staffing. ${ }^{1}$ Using data from 1996 to 2000, Konetzka et al. (2004) report that the introduction of the SNF PPS in 1998 had negative effects on the sum of RN and LPN hours. However, the SNF PPS had differing impacts on facility payments, with some facilities experiencing increases in payments and others experiencing decreases (White 2005). White (2005) uses simulated facility-specific payment changes to disentangle the effects of changes in payment levels, and reports that payment increases raised direct care staffing. However, the primary source of variation in the simulated payments is year-by-year revisions in the HWI routinely implemented by the Centers for Medicare and Medicaid Services (CMS) to reflect fluctuations of local labor market conditions (i.e., average wages), which are likely to be correlated with facilities' supply decisions. Hence, the payment changes in White (2005) are potentially related to nurse staffing through local labor market channels like the ease of recruiting nurses, in addition to the direct payment channel. Related to these prior works, Kaestner and Guardado (2008) study hospital nurse staffing levels in response to hospital geographic reclassifications that increase the HWI and thus the Medicare payment rate. In contrast to the nursing facility studies, they find that higher Medicare payments reduced nursing staff levels at hospitals.

A number of other studies have examined the impact of Medicaid payment rates on nursing home staffing using various study designs. Some longitudinal studies using state fixed-effects models find that increases in Medicaid payments are associated with higher staffing (Grabowski et al. 2004; Feng et al. 2008). Because changes in state payment rates may be a response to higher facility costs or part of cost-containment efforts, other studies have employed instrumental variables methods to deal with endogeneity of this type. Harrington, Swan, and Carrillo (2007) use such an approach in a national sample of facilities from 2002, and find that increases in state Medicaid payments increase RN hours.

1 In addition, Zinn et al. (2008) examine the effect of Medicare PPS on administrative nurse staffing, or time spent by nurses in activities other that direct care giving, in the nursing home setting. That study finds that the introduction of Medicare PPS increased administrative nurse staffing. 


\section{AMERICAN JOURNAL OF HEALTH ECONOMICS}

Hackmann (2019) uses exogenous variation in Medicaid reimbursement rates across Pennsylvania nursing homes in 2000-02 and finds that a 10 percent increase in Medicaid rates increases skilled nurse staffing per resident by 8.7 percent.

In summary, prior studies on Medicare payment rate changes find opposite-signed effects on staffing in hospitals and nursing homes. The literature on Medicaid payment and staffing generally finds that higher payments increase staffing, but these studies vary considerably in terms of identification strategies, and the most recent work in this area uses a single-state setting. Our study uses national data from a more recent time period to examine the effect of Medicare payment changes on nursing facility staffing. Our key contribution is the use of an improved strategy for identifying the causal effects of Medicare payment changes on facility staffing, as we describe in the next section.

\section{Nursing Facility Price Shocks}

\section{A. MEDICARE PAYMENT TO NURSING FACILITIES}

For patients enrolled in fee-for-service Medicare, Medicare reimburses facilities according to the SNF PPS, which was introduced in 1998 and replaced the prior cost-based system of payment. Under the PPS, facility payments from Medicare are determined by daily base rates defined separately for urban and rural facilities and are updated annually based on nationwide inflation. Starting in 2012 and under the ACA, the annual updates to the base payments are reduced to account for economy-wide productivity increases; these "productivity adjustment factors" in Medicare payment systems are the source of substantial savings in the ACA (Capretta and Antos 2015).

To account for differences in labor costs across the United States, a portion of the base rate is adjusted by the hospital wage index (HWI) in the area in which the facility is located (MedPAC 2018). In 2006, which is the midpoint of our sample period, 76 percent of the base rate was adjusted by the HWI (Medicare Prospective Payment System and Consolidated Billing for Skilled Nursing Facilities 2006). Figure 1 shows the relationship between the per diem SNF payment and the HWI, and equation 1 expresses it algebraically:

$$
P P S=H W I \times 0.76 \times b_{U}(r)+0.24 \times b_{U}(r)
$$

where $b_{U}(r)$ represents the base payment adjusted for the case mix of the patient; this base payment differs by the urban/rural status of the SNF. ${ }^{2}$

The HWI is calculated by CMS as the ratio of the area's average hourly hospital wage to the national average hourly hospital wage, where average hourly wages are derived from

2 The base payment is adjusted for case mix using resource utilization groups (RUGs). In 2019, there were 66 different RUGs, which reflect the varying resources needed to treat patients with different therapy and nursing needs, medical conditions, and cognitive and physical functioning (MedPAC 2018). Effective October 2019, CMS will use a new case mix system called PDPM or Patient-Driven Payment Model (Centers for Medicare and Medicaid Services 2018b). Effective October 2018, CMS adopted the SNF Value-Based Purchasing (VBP) Program, which adds bonuses or subtracts penalties based on each facility's 30-day all-cause hospital readmission rate (Centers for Medicare and Medicaid Services 2018c). 


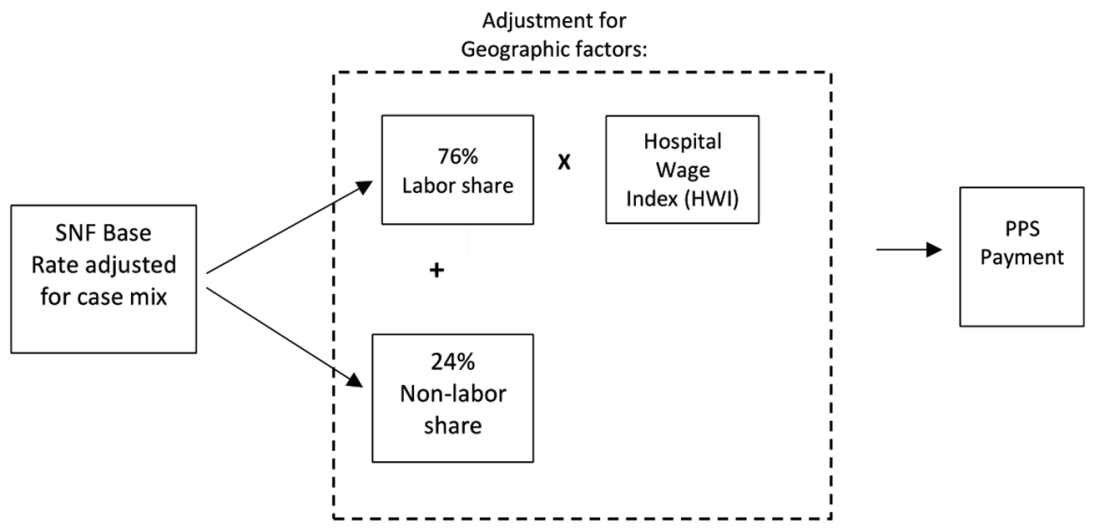

FIGURE 1. Illustration of the relationship between the HWI and the Medicare SNF PPS payment. Source: Adapted from MedPAC (2018).

data on wages, salaries, benefits, and hours reported by short-term acute care hospitals paid under the inpatient PPS on their annual Cost Reports (MaCurdy et al. 2009). Thus, facilities located in areas where hospital wages exceed the national average have wage index values greater than 1, and their payments are adjusted upward; facilities located in relatively low-cost areas have HWI values below 1 and receive lower payments.

\section{B. GEOGRAPHIC REALIGNMENT}

Since the HWI is an area-level adjustment, CMS must also establish how geographic areas are defined. Prior to federal fiscal year (FY) 2006, CMS defined the areas using metropolitan statistical areas; that is, the wage index value was based on costs in the MSA, and all facilities in the same MSA had the same HWI value applied to their payment determinations. Then, starting with federal FY 2007 (on October 1, 2006), CMS used core-based statistical areas in defining and applying HWI adjustments. During the transitional year of FY 2006 (between October 1, 2005, and September 30, 2006), CMS used a blended HWI adjustment equal to the average of MSA-based and CBSA-based wage index values (Medicare Prospective Payment System and Consolidated Billing for Skilled Nursing Facilities 2007). Under both MSA and CBSA geographies, regions outside of a metropolitan/urban area are grouped into one of 50 "rest-of-state" areas (i.e., one for each state).

The switch from MSAs to CBSAs had two effects on Medicare payments to facilities. First, because it altered the composition of the areas, the geographic realignment changed the value of the area-level HWI applied to facility per diem payment rates for thousands of facilities. For example, numerous facilities inside relatively low-wage MSAs (with relatively low HWIs) instead became part of higher-wage CBSAs, leading to increases in the HWI, while many other facilities in relatively high-wage MSAs become part of lower-wage CBSAs (leading to decreases in HWI). Figure 2 shows these HWI changes at the county level; for each county, the map displays the change in HWI following the switch from MSAs to CBSAs in the wage index calculation. Geographic regions across the United States experienced both increases and decreases of varying magnitudes. Second, the switch from 
AMERICAN JOURNAL OF HEALTH ECONOMICS

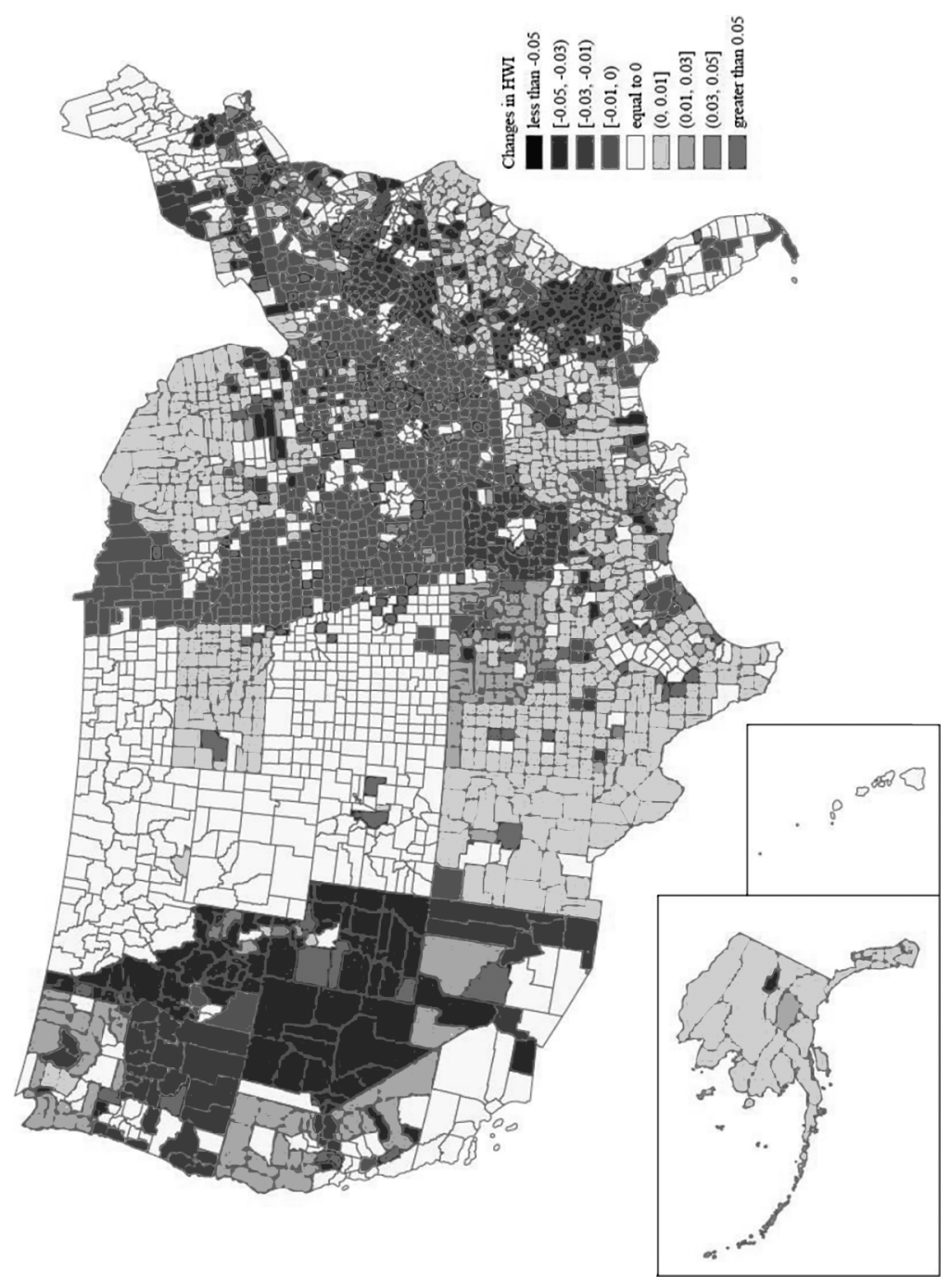

ह

는 응

ฮ

穴

옹 뇽

乐 웅

을 올

ס্ ভ

ज约

ज

으 본

䒕

넝 엉

Uु

in जे

은

군은

ij

ㄴํำ

그웜

흥

空

엉

ลิ

जा

드 ह

․ㅗㄴ

造 क

它

๗ึ ह

으

ते

割

约迅

过 응

๑

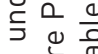

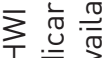

ᄃ 어

$\subseteq \underline{\omega} \underline{\sim}$

U $\leq \frac{1}{1}$

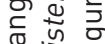

등

을

ㄱ $\frac{\pi}{4}$

山 ه

똑은 은

을 인 
MSAs to CBSAs affected base rates for a small group of facilities. In some cases, facilities previously designated as rural were designated as urban (and vice versa); since base payments are different for rural facilities and urban facilities, base payments either fell or rose in such instances.

Our identification strategy focuses on the first component of the Medicare payment change - the change in the HWI for individual SNFs resulting solely from the geographic realignment. In doing so, we exclude the small group of facilities for which the urban/rural designation switched (813 facilities). The reason for this exclusion is that under the geographic realignment when a facility switched from rural to urban designation (or vice versa), both the base payment and the HWI changed. Base payments differ by resource utilization group, so information on the RUG distribution at the facility level would be necessary to calculate payment changes for facilities that switch between urban and rural designation. Since the facility-specific RUG distribution is not easy to measure and the switchers account for a small number of facilities, we focus on the vast majority of facilities whose ru$\mathrm{ral} /$ urban classification remained unchanged. Importantly, these changes in the HWI led to changes in Medicare facility payments that were independent from the choices made by facilities and from the market conditions that facilities face. Equation 2 defines the change in the SNF PPS per diem rate relative to the initial rate (referred to as the "payment change" for simplicity). Substituting equation 1 for PPS and simplifying, we can express the percentage payment change as a function of the percentage point change in HWI:

$$
\Delta \text { Payment }=\frac{P P S_{1}-P P S_{0}}{P P S_{0}}=\frac{0.76 \Delta H W I}{0.76 H W I_{0}+(1-0.76)}
$$

For example, a facility whose HWI increased from 1.1 to 1.15 saw a 3.53 percent rise in the per diem payment rate, while a facility whose HWI fell from 0.95 to 0.90 saw a 3.95 percent drop in the per diem rate (all else equal). Our identification strategy is similar to that of Clemens and Gottlieb (2014), in that we use this geographic change in the application of the wage index to examine provider responses to Medicare payment changes.

Figure 3 illustrates the effects that the geographic realignment had on the HWI values for the nursing facilities in our sample. Each point represents a specific facility. The horizontal axis shows each facility's 2006 HWI when the MSA is used to assign the facility to a market; the vertical axis shows the facility's 2006 HWI when the CBSA is used. Points off of the 45-degree line indicate changes in HWI values generated by the geographic realignment, and thereby policy-induced changes in payment rates. Facilities across the whole range of MSA-based HWI values experienced changes in the HWI, and those changes included both increases and decreases. Using equation 2, we calculate the percentage change in Medicare payment associated with the HWI change; the distribution of Medicare payment changes is reported in Table 1. Nearly two-thirds of facilities experienced changes due to the policy, and some changes were quite large: 275 or 2.1 percent of nursing facilities saw payment increases or decreases of more than 5 percent. Another 5.5 percent of facilities experienced increases or decreases of more than 3 percent, and nearly 11 percent experienced increases or decreases ranging from 1 percent to 3 percent. These changes, though appearing small in magnitude, are important for facility profit margins. MedPAC (2017) estimated the average SNF profit margin to be 1.6 percent in 2015. 


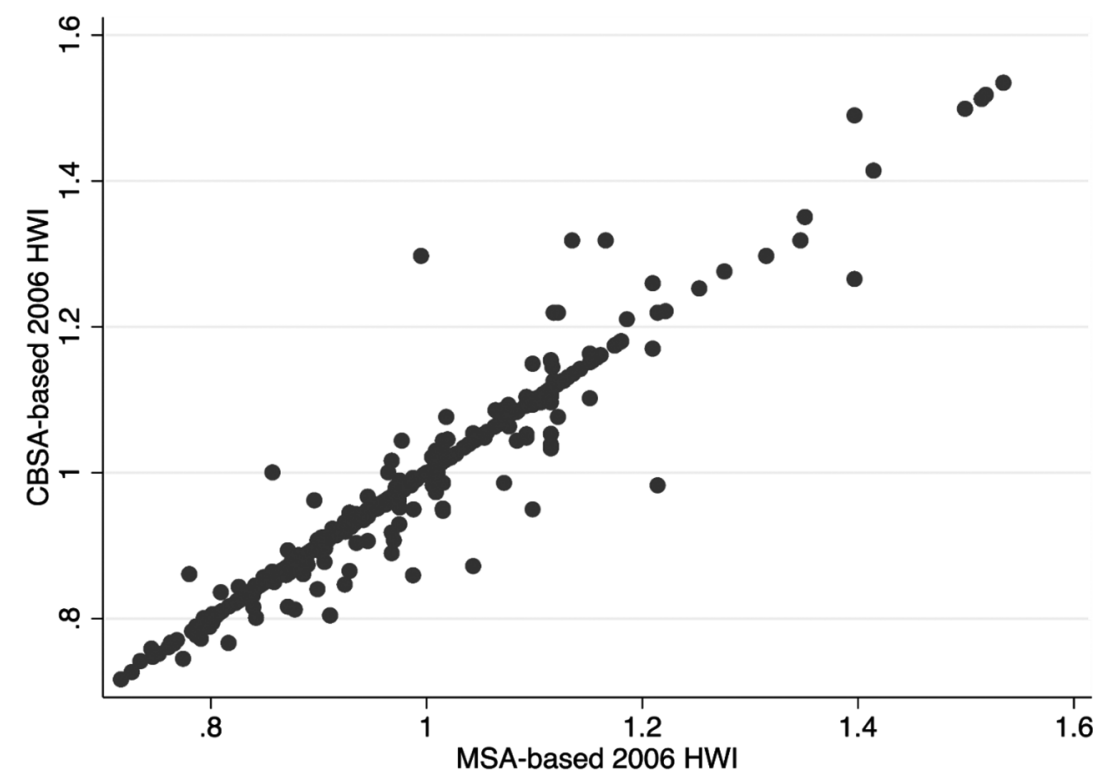

FIGURE 3. HWI under MSA and CBSA definitions. The figure shows the relationship between the MSA-based HWI and the CBSA-based HWI in 2006 for 13,023 nursing facilities. A color version of this figure is available online.

TABLE 1. Geography-induced change in 2006 Medicare payment

\begin{tabular}{lcc}
\hline Change in Medicare payment & No. of nursing facilities & Share of nursing facilities \\
\hline $\begin{array}{l}\text { Decreases } \\
\Delta \text { Payment less than }-0.05\end{array}$ & 140 & 1.1 \\
$\Delta$ Payment in $[-0.05,-0.03)$ & 326 & 2.5 \\
$\Delta$ Payment in $[-0.03,-0.01)$ & 874 & 6.6 \\
$\Delta$ Payment in $[-0.01,0)$ & 3,735 & 28.3 \\
No change & 4,631 & 35.1 \\
& & \\
Increases & & 20.4 \\
$\Delta$ Payment in $(0,0.01]$ & 2,688 & 4.2 \\
$\Delta$ Payment in $(0.01,0.03]$ & 553 & 0.9 \\
$\Delta$ Payment in $(0.03,0.05]$ & 121 & 1 \\
$\Delta$ Payment greater than 0.05 & 135 & 100 \\
Total facilities & 13,203 & \\
\hline
\end{tabular}

Note: Sample excludes government-owned and in-hospital nursing facilities and facilities with missing data for RN hours per resident day and explanatory variables in the regressions. 
The switch from MSAs to CBSAs had differing effects on facilities located in urban and rural areas, even those that did not switch from one designation to the other. For example, some large MSAs got split into multiple CBSAs, and the most-urban of the new CBSAs saw the highest HWI increases. We tested this systemically by regressing the 2006 county-level HWI difference (the CBSA-based HWI minus the MSA-based HWI) on the county share of the population living in urban areas, controlling for state fixed effects; the coefficient estimate for county urban share was positive and significant. Therefore, to address the possibility of differential trends across urban and rural areas that could contribute to differences in staffing, we control for time-varying urban-rural differences in our model, as we note below. Our estimates also account for persistent location differences with facilitylevel fixed effects.

To the best of our knowledge, the present study is the first to exploit the plausibly exogenous variation in the HWI caused by Medicare's shift from MSAs to CBSAs to study the effects of Medicare payment on nursing home staffing. A few studies have examined the effects of the HWI geography change on other health-care provider decisions. McHenry and Mellor (2018) use the same geographic change to test whether hospitals strategically game the wage index adjustment by paying higher wages to nurses. Shin (2019) and $\mathrm{He}$ et al. (2020) use similar geographic realignments to examine the impacts of Medicare payment changes on the volume of care provided to Medicare patients by hospitals and SNFs, respectively. ${ }^{3}$

\section{Conceptual Framework}

In this section, we provide a simple theoretical framework for understanding the effects of Medicare payment changes on SNF staffing decisions. Following Sloan (2000), we assume that the facility maximizes the weighted sum of profits and quality of care. Revenue is derived from two types of services, post-acute care $(P A)$ and long-stay care $(L S)$, the prices of which $(p)$ may differ. We assume that facilities take output prices as given, and that the price of post-acute care is determined by Medicare reimbursement policy. Output

3 The nursing home setting offers a cleaner identification strategy compared with the hospital setting. Hospitals can circumvent changes in the HWI that would otherwise reduce their payments by seeking geographic reclassification to a different area with a higher HWI. Additionally, hospitals can also receive a number of adjustments to the HWI. The rural floor provision holds that hospitals in urban areas within a state cannot be assigned an HWI lower than the HWI used in rural areas. Under the out-migration adjustment, CMS adjusts the wage index applied to hospital payments based on commuting patterns of hospital employees. The occupational mix adjustment adjusts the index based on the mix of hospital employees. Estimates suggest that almost 40 percent of hospitals paid under the inpatient prospective payment system receive some kind of adjustment or reclassification so that the wage index applied to payment calculations is different from the index of their geographic location (Institute of Medicine 2012). In contrast, federal regulations do not allow administrative adjustments to the HWI in the case of nursing facility payment, thus strengthening our ability to identify causal effects of payment changes (Medicare Prospective Payment System and Consolidated Billing for Skilled Nursing Facilities 2005a, 2005b, 2007). 


\section{AMERICAN JOURNAL OF HEALTH ECONOMICS}

quantities are $q$ and the level of staffing (i.e., labor input) is $L .{ }^{4}$ Wages are $w$ and are taken as determined in a competitive labor market. Quality of care is $\nu$, which rises with staffing.

The nursing home maximizes its institutional utility (with the weight on profits denoted by $\alpha$ ):

$$
\max _{L} \alpha\left[p_{P A} q_{P A}(L)+p_{L S} q_{L S}(L)-w L\right]+(1-\alpha) \nu(L)
$$

The first-order necessary condition is the following:

$$
\alpha\left(p_{P A} \frac{\partial q_{P A}}{\partial L}+p_{L S} \frac{\partial q_{L S}}{\partial L}-w\right)+(1-\alpha) \frac{\partial \nu}{\partial L}=0
$$

An increase in staffing increases output quantity and thereby increases profit, but that comes at a marginal cost of higher payroll. An increase in staffing also increases quality. The facility chooses the optimal level of staffing to balance weighted marginal costs and benefits.

Our empirical analysis estimates the effect of a Medicare reimbursement rate change on staffing. In the framework above, an increase in $p_{P A}$ increases the marginal benefit of post-acute services, which increases the marginal revenue product of staffing. The facility would likely respond by increasing its staffing level. Conversely, a decrease in the reimbursement rate would decrease the marginal revenue product of staffing inputs and might decrease the staffing level. However, it is possible that the facility independently values quality of care enough to mitigate any reduction in staffing from reimbursement cuts. The model incorporates such a mitigation with the possibility that the weight on profits $(\alpha)$ is small, or the effect of staffing on quality of care $\partial \nu / \partial L$ is large.

Facilities vary in the share of total services provided to post-acute patients reimbursed by Medicare. Our conceptual framework implies that if marginal labor inputs are used less for post-acute than for long-stay patients, then the marginal product of labor for postacute services will be smaller than that for long-stay services $\left(\partial q_{P A} / \partial L<\partial q_{L S} / \partial L\right)$. In such a case, the influence of Medicare reimbursement on staffing will be smaller. But for facilities with a larger Medicare share, the influence of Medicare reimbursement changes on staffing will be larger. This observation informs our identification strategy that compares plausibly exogenous changes in Medicare reimbursement rates across facilities with higher versus lower Medicare shares.

\section{Estimation}

To estimate the effects of Medicare SNF payment changes on nursing staff levels, we estimate equation 5 :

$$
\begin{aligned}
& y_{i t}= \alpha_{1} \text { SPayment }_{i} \times \text { POST }_{t} \times \text { Medicare Share }_{i}+\alpha_{2} \text { SPayment }_{i} \times \text { POST }_{t} \\
&+\alpha_{3} \text { POST }_{t} \times \text { Medicare Share } \\
& i
\end{aligned}
$$

4 In this conceptual framework, we assume that labor inputs are used interchangeably for post-acute and long-stay care, rather than specializing in either type of care. This is consistent with the measures of facilitylevel staffing available to us. 
where $i$ denotes the facility and $t$ denotes the time period. Our sample includes three years prior to the FY 2006 change in the construction of the HWI (2003-05) and three years after the change (2007-09), and we omit 2006, where an average of MSA-based HWI and CBSA-based HWI was used. Our sample period ends in 2009 so that the implementation of the ACA does not confound our analysis. The dependent variable, $y_{i t}$, is one of several staffing measures, including RN hours per resident day (HPRD), LPN HPRD, and total direct care staff HPRD. We define these in more detail in Section VI.

The key explanatory variable in the regression is the interaction of $\triangle$ Payment $_{i}, P O S T_{t}$, and Medicare Share ${ }_{i} . \Delta$ Payment $_{i}$ is the percentage change in per diem Medicare payment rates to SNF caused by the change in HWI, and calculated with equation 2. POST $T_{t}$ is a binary variable indicating years after the realignment (2007-09). ${ }^{5}$ Medicare Share ${ }_{i}$ is the facility-specific share of Medicare days, or the ratio of resident days paid by Medicare to total resident days, defined for 2005, the calendar year prior to the geographic change. The average Medicare share in our sample is 14.5 percent in 2005. This variable measures the "exposure" of a facility to the Medicare payment change, as facilities with an initially higher Medicare share are more heavily affected by Medicare payment changes than facilities with an initially lower Medicare share. ${ }^{6}$ Thus, the estimate of $\alpha_{1}$ measures the difference in the effect of the payment change by facilities' exposure to Medicare. ${ }^{7}$

We include a large number of controls in the model. $X_{i t}$ represents a set of time-varying facility and county traits. Time-varying facility traits include the number of certified beds and indicator variables for whether the facility is part of a chain or is a nonprofit. Timevarying county traits include nursing home beds per 1,000 residents age 65 and older, home health agencies per 1,000 residents age 65 and older, shares of the county population

5 CMS uses the fiscal year and most of our other data sources are based on the calendar year (CY). Although a given fiscal year runs from October 1 of the past calendar year through September 31 of the current calendar year, we do not think this misalignment poses a serious threat to our identification, as most of the CY and FY overlap.

6 At the suggestion of an anonymous referee, we used a measure of Medicare revenue in the construction of our key explanatory variable in equation 5, in place of the change in the Medicare payment rate interacted with the Medicare share. This change facilitates the interpretation of the coefficient estimates. We estimated these models and obtained results (available upon request) that are consistent with the main estimates from equation 5. However, because the construction of facility-level Medicare revenue relies on a strong simplifying assumption, we report results from using the triple interaction term in equation 5 as our main explanatory variable. Specifically, to construct facility-level Medicare per diem rates we need data on the facility's case mix of Medicare patients, among other measures. We are unable to measure the case mix of Medicare patients in our data, so we used the facility-level average RUG as a proxy. This assumes that the facility-level average RUG for all patients (short-stay Medicare patients and long-stay patients) is the same as the average RUG for Medicare patients.

7 Our identification strategy relies on changes in HWI at the geographic level. While facilities in the same location experienced a similar policy change, our strategy of measuring the facility's exposure to the policy change by its Medicare share allows us to exploit within-location variation in the policy change as well, since nearby facilities with different Medicare shares were affected differentially by the policy. We confirmed in our sample that a substantial share of the variation in our main independent variable occurs within geographic areas defined by hospital service areas (HSAs). 


\section{AMERICAN JOURNAL OF HEALTH ECONOMICS}

that are female, African American, Hispanic, under age 65, and in poverty, the Medicare Advantage penetration rate, and the employment-to-population ratio. In addition, $X_{i t}$ also includes interactions between each of the year dummies and a measure of the share of the county population residing in areas designated as urban. This allows for differential urbanrural trends, since, as noted earlier, the impacts of the HWI geographic realignment had differing effects on facilities located in urban and rural areas. To capture all time-invariant factors at the facility level, such as geographic location and management style, we include $\gamma_{i}$, a set of facility fixed effects. We include a set of year dummies (represented by $\tau_{\mathrm{t}}$ ) to pick up annual changes in staffing affecting all facilities nationwide. $\lambda_{s t}$ represents a full set of state-by-year dummy variables, which capture all factors that change at an annual level and affect all nursing facilities in the same state the same way, such as state-specific macroeconomic fluctuations, demographic trends, and policy changes. $\varepsilon_{i t}$ is the error term.

We estimate the model for Medicare/Medicaid certified nursing homes across the United States. ${ }^{8}$ We exclude in-hospital facilities and government-owned facilities from our sample since these facilities may differ in important ways from the rest of the market. ${ }^{9}$ As noted above, we also exclude 813 facilities whose designation as urban or rural switched as a result of the geographic realignment. Those facilities experienced base rate shifts (between the rural- and urban-specific base rates) in addition to the HWI change. We weight observations in the regressions by the number of Medicare/Medicaid certified beds. We cluster the standard errors at the level of the unique MSA-CBSA pairs in our sample.

\section{Data}

Our primary data source is LTCFocus.org. ${ }^{10}$ For the staffing measures we use, LTCFocus draws from the Online Survey Certification and Reporting (OSCAR)/Certification and Survey Provider Enhanced Reporting (CASPER) data. OSCAR/CASPER data are collected by state agencies as part of annual certification inspections of nursing homes and are maintained by CMS. We include three measures of staffing, each defined as hours per resident day (HPRD): RN HPRD, LPN HPRD, and total direct care staff (DC) HPRD. DC staff hours are defined as the sum of RN, LPN, and certified nursing assistant (CNA) hours. ${ }^{11}$

8 Because they are not included in LTCFocus.org, our main data source, facilities in Alaska and Washington, DC, are excluded.

9 For example, because of the close connection between hospital-based nursing homes and the hospitals where the home is located, the former may consider both hospital and facility objectives, which will affect responses to Medicare payment changes. The literature has often treated the freestanding nursing facilities separately from the hospital-based nursing facilities (e.g., Konetzka et al. 2006; White 2005). Of all facilities in 2005, 6 percent were government owned and 9 percent were in-hospital facilities.

10 LTCFocus.org is produced by the Shaping Long-Term Care in America Project at Brown University, funded in part by the National Institute on Aging (1P01AG027296).

11 In constructing these measures, LTCFocus converts CMS versions of the survey responses of facilities into measures of the number of RN (or LPN or CNA) HPRD. In the process LTCFocus inspects the data for implausible values and sets these variables to missing in certain cases, and imputes values for certain cases when the facility's data exhibit sizable variations from one year to the next (specifically when the staffing is 
We calculated the HWI change used to identify the payment changes from published data in the Federal Register (Medicare Prospective Payment System and Consolidated Billing for Skilled Nursing Facilities 2007). These data provide each county's MSA assignment, CBSA assignment, 2006 MSA-based wage index, and 2006 CBSA-based wage index. $\Delta H W I_{i}$ is defined as the 2006 CBSA-based HWI minus the 2006 MSA-based wage index, and is used in equation 2 to calculate $\Delta$ Payment ${ }_{i}$. We then merged these county-level data to facilities in LTCFocus by county code. ${ }^{12}$

For the facility's Medicare share in 2005, we used a variable from LTCFocus measuring the share of SNF Medicare days out of the total number of nursing home days for all residents in the facility in the calendar year. This variable was obtained from the Residential History File (RHF), which is constructed from Medicare enrollment and claims data and the Minimum Data Set (MDS). Additional details on construction of the RHF are available in Intrator et al. (2010).

We obtain facility-level data on ownership type, membership in a chain, and bed size from annual Nursing Home Compare data. ${ }^{13}$ We extract county-level data on demographic and economic characteristics of the population, as well as hospital beds and home health agencies per 1,000 residents age 65 and older from the Area Health Resource File (AHRF). We obtain county-year data on the Medicare managed care organization penetration rate from LTCFocus, which includes AHRF data originally from CMS. We construct annual measures of county employment-to-population ratios from US Census $\mathrm{Bu}$ reau data, namely, County Business Patterns data on the number of employees per county and intercensal estimates of the county population. We obtain data on the county's urban share in 2000 from the US Census Bureau and data on the county's metro status from Mable/Geocorr 2000.

In additional analysis, we examine several other quality measures and a measure of resident days. The first two quality measures are counts of life safety deficiencies and health

less than one-third or more than three times the median of previous years). Documentation from LTCFocus (Datadictionary.xlsx, row 235) specifically notes: "Facilities report the number of Registered Nurse (RN) hours during the two weeks prior to their annual survey. CMS converts the number of hours into full-time equivalents (based on a 35-hour work week) and this is what is reported on the annual OSCAR or CASPER data. We convert the FTEs back into hours, by multiplying by 35 , and divide the total number of RN hours by the number of residents in the facility (also drawn from the OSCAR or CASPER) to arrive at the RN hours per resident day (HPRD). We also clean this variable when the FTEs reported are implausible. We set to missing when total FTEs are 995 or higher or if there are more RN and LPNs reported than the number of beds in a facility. We also verify staffing variables based on a facility's data from previous years and impute based on previous data if staffing levels are less than $1 / 3$ the median of previous years or greater than 3 times the median, for example. For county and state this is the average RN HPRD among all facilities."

12 Given the importance of having accurate measures of facility-specific changes and the county-level nature of these data, we validated the county code in LTCFocus against two other sources of nursing facility data with county codes: CMS Skilled Nursing Facility Cost Reports and Nursing Home Compare. For most facilities, the three sources listed the same county. For cases where discrepancies existed across the three sources, we conducted manual lookups of street addresses to obtain the correct county.

13 In cases in which Nursing Home Compare data were missing, we used the LTCFocus data to fill in the missing values. 


\section{AMERICAN JOURNAL OF HEALTH ECONOMICS}

deficiencies, respectively. ${ }^{14}$ We obtain these variables from the Nursing Home Compare Calendar Year Provider Standard Surveys and Deficiency Files from CMS, which are based on monthly extracts of the OSCAR database. Since the unit of analysis in each calendar year's data is the survey, not the provider, and surveys can be 9 to 15 months apart, we construct these variables following the procedures in the Online Appendix;. Following Konetzka et al. (2004) and White (2005), we also examine several Nursing Home Compare quality measures (QMs): these include three measures of the percentage of residents with pressure ulcers, defined for high-risk long-stay residents, low-risk long-stay residents, and short-stay residents, plus the share of long-stay residents who were physically restrained. ${ }^{15,16}$ We obtain data on resident days from the SNF Cost Reports following the procedures described in the Online Appendix;.

Table 2 reports summary statistics for the roughly 13,000 facilities in our sample in 2005. On average, facilities report 0.31 hours per resident day for RNs, 0.75 hours per resident day for LPNs, and 3.23 hours per resident day for direct care staff. For comparison, the minimum federally recommended staffing levels by CMS are $0.75,0.55$, and 4.1 hours for RNs, LPNs, and direct care staff, respectively (Centers for Medicare and Medicaid Services 2001). ${ }^{17}$ The average Medicare share of patient days is 14.5 percent, similar to national statistics. Across all facilities, the average payment change is a decrease of 0.0014 (that is, 0.14 percent) but as noted in Table 1, there is considerable variation across our sample. In additional columns of Table 2, we compare facilities experiencing payment decreases of 1 percent or more and those experiencing payment increases of 1 percent or more to facilities with more modest or zero payment changes (payment changes ranging from -1 percent to 1 percent, including no change). Facilities in all three groups had similar mean staffing levels in 2005. Facilities with modest payment changes had a lower Medicare share than those with larger payment changes, but the difference is small

14 Examples of life safety deficiencies (also known as "K-tags") include inspection citations related to fire alarms, sprinkler systems, utilities and cook facilities, door design related to smoke/fire, and means of egress, among others. Examples of health deficiencies (also known as "F-tags") include citations related to infection control, accident environment, food safety, quality of care, and pharmacy consultation, among others.

15 We chose these from 15 QMs that were available in 2005 (and thus before the payment change we examine). Since our identification strategy relies on the payment change that took place in 2006, it is not possible for us to use other QMs introduced in that year. We construct annual facility-specific measures by averaging quarterly data obtained from CMS. For 2003, we have only two quarters of Nursing Home Compare QM data; in all other years in our panel we have all four quarters of QM data.

16 Additional long-stay quality measures include the percentage of residents (1) whose need for help with daily activities has improved, (2) who have moderate/severe pain, (3) who lose control of bowels/bladder, (4) who have/had a catheter inserted and left in their bladder, (5) who spend most time in a bed or chair, (6) whose locomotion has worsened, (7) who have a urinary tract infection, (8) who are more depressed or anxious, and (9) who lose too much weight. Two other short-stay quality measures are the percentage of residents (1) with delirium, and (2) who had moderate to severe pain. We also estimate models of these 11 measures in a robustness check described in the Section VII.

17 These are recommended minimum staffing levels from a 2001 CMS report (cited in Harrington et al. 2016). Various states have implemented legally binding minimum staffing levels (Bowblis 2011); the state legal minimum levels are not always expressed in terms of hours per resident day. 
(14.4 percent compared with about 15 percent). Across the three groups, there are a number of statistically significant differences in other facility traits such as size, chain status, and ownership, but these differences are generally small. It is important to note that our identification strategy relies on within-facility payment changes induced by the geographic realignment; therefore, all time-invariant facility-specific traits are controlled for.

\section{Results}

\section{A. MAIN SPECIFICATION RESULTS}

Table 3 reports the results from estimating equation 5. In addition to the covariates listed in the table, the model also includes facility fixed effects, year fixed effects, state-by-year fixed effects, and a set of interactions between year indicators and the county's urban share. The estimated coefficient for the key explanatory variable - interaction of the percentage payment change, baseline Medicare share, and an indicator for years after the policy change-is reported in the first row. In all three models, the coefficient estimates for the key explanatory variable are positive, consistent with payment increases leading to higher staff hours per resident day. The estimates are statistically significant in the models of RN and LPN hours per resident day.

To interpret the effect sizes, we simulate the effects of a 5 percent payment increase for facilities with a Medicare share of 10 percent relative to 0 percent. This is a relatively large change - only 2.1 percent of facilities have payment changes larger than 5 percent, and a 10 percentage point change in Medicare share is approximately equal to the median Medicare share and its interquartile range. The simulated effects are reported in Table 3 and show that this 5 percent payment increase raised RN hours per resident day by 9.01 percent (and LPN hours per resident day by 3.24 percent) in facilities with 10 percent of resident days paid by Medicare relative to facilities with no Medicare patients. These effects are similar to responses by Pennsylvania nursing homes to changes in Medicaid payment rates reported in prior work. Specifically, Hackmann (2019) finds that a 5 percent increase in Medicaid payments increased skilled nursing staff by 4.35 percent, which lies between our estimates.

Some of the other coefficient estimates reported in Table 3 are statistically significant. Increases in beds are associated with decreases in staffing hours per resident day, perhaps explained by scale economies. Staffing is significantly lower for facilities that are part of a chain, and staffing decreases as Medicare Advantage penetration increases. The estimated coefficients for the interaction term between the payment change and POST are small for the LPN and direct-care specifications, suggesting that changes in Medicare payments have near-zero effects at facilities that do not treat Medicare patients. However, a 5 percent payment increase is estimated to reduce RN HPRD at zero-Medicare facilities by 0.04 , which is about 13 percent of the mean; our conjecture is that the linear Medicare share term may be somewhat misspecified in the $\mathrm{RN}$ model, although we also note that the confidence interval includes quite small effects at zero-Medicare facilities. The estimated coefficients for the baseline Medicare share interacted with the POST indicator are negative and significant, indicating that higher Medicare share nursing facilities decreased staffing levels in the post period, even for facilities that did not experience changes in the HWI 
TABLE 2. Descriptive statistics, nursing facilities in 2005

\begin{tabular}{|c|c|c|c|c|}
\hline & $\begin{array}{l}\text { All facilities } \\
\text { (1) }\end{array}$ & $\begin{array}{c}\text { Facilities with } \\
\text { large payment } \\
\text { decreases } \\
\text { (2) }\end{array}$ & $\begin{array}{c}\text { Facilities with } \\
\text { small payment } \\
\text { changes } \\
\text { (3) }\end{array}$ & $\begin{array}{c}\text { Facilities with } \\
\text { large payment } \\
\text { increases } \\
\text { (4) }\end{array}$ \\
\hline \multicolumn{5}{|l|}{ Staffing variables } \\
\hline \multirow[t]{3}{*}{$\begin{array}{l}\text { RN hours per resident } \\
\text { day (RN HPRD) }\end{array}$} & 0.305 & 0.311 & 0.303 & 0.317 \\
\hline & {$[0.371]$} & {$[0.274]$} & {$[0.387]$} & {$[0.278]$} \\
\hline & 12,956 & 1,300 & 10,856 & 800 \\
\hline \multirow[t]{3}{*}{$\begin{array}{l}\text { LPN hours per resident } \\
\text { day (LPN HPRD) }\end{array}$} & 0.754 & 0.748 & 0.757 & $0.719^{c}$ \\
\hline & {$[0.531]$} & {$[0.475]$} & {$[0.550]$} & {$[0.297]$} \\
\hline & 12,952 & 1,300 & 10,852 & 800 \\
\hline \multirow[t]{3}{*}{$\begin{array}{l}\text { Direct-care staff hours per } \\
\text { resident day (DC HPRD) }\end{array}$} & 3.228 & $3.304^{\mathrm{a}}$ & 3.223 & 3.168 \\
\hline & {$[0.973]$} & [1.017] & [0.983] & {$[0.722]$} \\
\hline & 12,931 & 1,299 & 10,833 & 799 \\
\hline Explanatory variables & $N=12,956$ & $N=1,300$ & $N=10,856$ & $N=800$ \\
\hline $\begin{array}{l}\text { Change in Medicare } \\
\text { payment ( } \Delta \text { Payment })\end{array}$ & -0.0014 & $-0.031^{\mathrm{a}}$ & -0.00047 & $0.034^{\mathrm{a}}$ \\
\hline Medicare share & 0.145 & 0.149 & 0.144 & $0.153^{\mathrm{b}}$ \\
\hline $\begin{array}{l}\text { Facility no. of Medicare/ } \\
\text { Medicaid certified beds }\end{array}$ & 110.320 & $127.210^{\mathrm{a}}$ & 108.200 & $111.700^{c}$ \\
\hline Facility is part of a chain & 0.563 & $0.515^{\mathrm{a}}$ & 0.574 & $0.493^{\mathrm{a}}$ \\
\hline Facility is nonprofit & 0.256 & 0.265 & 0.260 & $0.199^{\mathrm{a}}$ \\
\hline $\begin{array}{l}\text { County no. of beds per } \\
1,000 \text { persons age } 65+\end{array}$ & 26.308 & $24.363^{\mathrm{a}}$ & 26.542 & 26.296 \\
\hline $\begin{array}{l}\text { County no. of home } \\
\text { health agencies per } \\
1,000 \text { persons age } 65+\end{array}$ & 0.254 & $0.208^{\mathrm{a}}$ & 0.261 & $0.226^{\mathrm{a}}$ \\
\hline $\begin{array}{l}\text { County under age } 65 \\
\text { share of the population }\end{array}$ & 0.865 & 0.863 & 0.865 & $0.869^{\mathrm{a}}$ \\
\hline $\begin{array}{c}\text { County female share } \\
\text { of the population }\end{array}$ & 0.508 & $0.511^{\mathrm{a}}$ & 0.508 & $0.509^{\mathrm{a}}$ \\
\hline $\begin{array}{l}\text { County African American } \\
\text { share of the population }\end{array}$ & 0.115 & $0.139^{\mathrm{a}}$ & 0.111 & $0.128^{\mathrm{a}}$ \\
\hline $\begin{array}{l}\text { County Hispanic share of } \\
\text { the population }\end{array}$ & 0.110 & $0.100^{\mathrm{a}}$ & 0.113 & $0.097^{\mathrm{a}}$ \\
\hline $\begin{array}{l}\text { County pop. share with } \\
\text { income }<100 \% \mathrm{FPL}\end{array}$ & 0.131 & $0.139^{\mathrm{a}}$ & 0.130 & 0.133 \\
\hline $\begin{array}{l}\text { County Medicare } \\
\text { Advantage penetration rate }\end{array}$ & 12.006 & $9.774^{\mathrm{a}}$ & 12.615 & $7.365^{\mathrm{a}}$ \\
\hline
\end{tabular}


TABLE 2. Continued

\begin{tabular}{|c|c|c|c|c|}
\hline & $\begin{array}{l}\text { All facilities } \\
\text { (1) }\end{array}$ & $\begin{array}{c}\text { Facilities with } \\
\text { large payment } \\
\text { decreases } \\
\text { (2) }\end{array}$ & $\begin{array}{c}\text { Facilities with } \\
\text { small payment } \\
\text { changes } \\
\text { (3) }\end{array}$ & $\begin{array}{c}\text { Facilities with } \\
\text { large payment } \\
\text { increases } \\
\text { (4) }\end{array}$ \\
\hline $\begin{array}{l}\text { County employment-to- } \\
\text { population ratio }\end{array}$ & 1.404 & $1.237^{\mathrm{a}}$ & 1.423 & 1.416 \\
\hline \multicolumn{5}{|l|}{ Additional quality variables } \\
\hline \multirow[t]{3}{*}{$\begin{array}{l}\text { Number of life safety } \\
\text { deficiencies }\end{array}$} & 3.887 & $2.988^{\mathrm{a}}$ & 3.973 & 4.193 \\
\hline & [3.975] & [3.340] & {$[4.010]$} & {$[4.260]$} \\
\hline & 12,712 & 1,285 & 10,650 & 777 \\
\hline \multirow[t]{3}{*}{$\begin{array}{l}\text { Number of health } \\
\text { deficiencies }\end{array}$} & 6.745 & 6.454 & 6.690 & $7.985^{\mathrm{a}}$ \\
\hline & {$[5.637]$} & {$[5.350]$} & {$[5.590]$} & {$[6.490]$} \\
\hline & 12,712 & 1,285 & 10,650 & 777 \\
\hline \multirow[t]{3}{*}{$\begin{array}{l}\text { Mean share of high-risk } \\
\text { long-stay residents with } \\
\text { pressure ulcers (QM 303) }\end{array}$} & 13.54 & $14.46^{\mathrm{a}}$ & 13.32 & $14.93^{\mathrm{a}}$ \\
\hline & {$[6.30]$} & {$[6.39]$} & {$[6.25]$} & {$[6.55]$} \\
\hline & 9,474 & 1,017 & 7,896 & 561 \\
\hline \multirow[t]{3}{*}{$\begin{array}{l}\text { Mean share of low-risk } \\
\text { long-stay residents with } \\
\text { pressure ulcers (QM 304) }\end{array}$} & 2.59 & $2.41^{\mathrm{b}}$ & 2.59 & $2.82^{c}$ \\
\hline & {$[2.36]$} & {$[2.18]$} & {$[2.37]$} & {$[2.56]$} \\
\hline & 7,204 & 820 & 5,940 & 444 \\
\hline \multicolumn{5}{|l|}{$\begin{array}{l}\text { Mean share of short-stay } \\
\text { residents with pressure }\end{array}$} \\
\hline & {$[8.24]$} & {$[8.38]$} & {$[8.27]$} & {$[7.28]$} \\
\hline & 9,330 & 1,000 & 7,781 & 549 \\
\hline \multirow[t]{3}{*}{$\begin{array}{l}\text { Mean share of long-stay } \\
\text { residents who are physically } \\
\text { restrained (QM 311) }\end{array}$} & 6.93 & 6.77 & 6.88 & $7.83^{\mathrm{a}}$ \\
\hline & {$[7.36]$} & {$[6.97]$} & {$[7.40]$} & {$[7.63]$} \\
\hline & 11,985 & 1,224 & 10,036 & 725 \\
\hline
\end{tabular}

Note: Means, standard deviations (in brackets), and sample sizes are reported. Samples exclude government-owned and in-hospital nursing facilities and facilities with missing data for RN HPRD or the explanatory variables in the regressions. Superscript letters in columns 2 and 4 report whether the mean in each column is significantly different from the mean in column 3 . ${ }^{a}$ indicates significance at the $1 \%$ level, ${ }^{b}$ at the $5 \%$ level, and ${ }^{c}$ at the $10 \%$ level. Large payment increases (decreases) are defined as increases (decreases) of $1 \%$ or more. Small payment changes are defined as those greater than $-1 \%$ and less than $1 \%$. 
TABLE 3. Effects of payment changes on staffing, main specification

\begin{tabular}{|c|c|c|c|}
\hline & $\begin{array}{l}\text { RN HPRD } \\
\text { (1) }\end{array}$ & $\begin{array}{l}\text { LPN HPRD } \\
\text { (2) }\end{array}$ & $\begin{array}{l}\text { DC HPRD } \\
\text { (3) }\end{array}$ \\
\hline \multirow[t]{2}{*}{$\Delta$ Payment $\times$ Post $\times$ Medicare Share } & $5.665^{\mathrm{a}}$ & $5.023^{\mathrm{a}}$ & 5.278 \\
\hline & $(1.713)$ & $(1.886)$ & $(5.388)$ \\
\hline \multirow[t]{2}{*}{$\Delta$ Payment $\times$ Post } & $-0.816^{\mathrm{a}}$ & -0.238 & -0.442 \\
\hline & $(0.303)$ & $(0.353)$ & $(0.929)$ \\
\hline \multirow[t]{2}{*}{ Post $\times$ Medicare Share } & $-0.293^{\mathrm{a}}$ & $-0.331^{\mathrm{a}}$ & $-0.245^{\mathrm{b}}$ \\
\hline & $(0.073)$ & $(0.081)$ & $(0.110)$ \\
\hline \multirow[t]{2}{*}{ No. of certified beds (facility) } & $-0.001^{\mathrm{a}}$ & $-0.002^{\mathrm{a}}$ & $-0.004^{\mathrm{a}}$ \\
\hline & $(0.000)$ & $(0.001)$ & $(0.001)$ \\
\hline \multirow[t]{2}{*}{ Chain (facility) } & $-0.008^{\mathrm{c}}$ & -0.008 & $-0.028^{\mathrm{c}}$ \\
\hline & $(0.004)$ & $(0.010)$ & $(0.016)$ \\
\hline \multirow[t]{2}{*}{ Nonprofit (facility) } & 0.002 & 0.011 & 0.027 \\
\hline & $(0.013)$ & $(0.026)$ & $(0.027)$ \\
\hline \multirow[t]{2}{*}{ Beds/1,000 age $65+$ (county) } & 0.000 & 0.000 & 0.000 \\
\hline & $(0.000)$ & $(0.000)$ & $(0.001)$ \\
\hline \multirow[t]{2}{*}{$\mathrm{HH} / 1,000$ age $65+($ county) } & -0.026 & -0.059 & $-0.064^{\mathrm{c}}$ \\
\hline & $(0.029)$ & $(0.057)$ & $(0.037)$ \\
\hline \multirow[t]{2}{*}{ Share $<$ age 65 (county) } & 0.220 & 0.313 & $-1.810^{c}$ \\
\hline & $(0.482)$ & $(0.708)$ & $(1.081)$ \\
\hline \multirow[t]{2}{*}{ Share female (county) } & 0.157 & -0.699 & -0.464 \\
\hline & $(0.527)$ & $(0.881)$ & $(1.575)$ \\
\hline \multirow[t]{2}{*}{ Share Afr. Amer. (county) } & $-0.764^{\mathrm{b}}$ & 0.088 & -2.021 \\
\hline & $(0.308)$ & $(0.864)$ & $(1.400)$ \\
\hline \multirow[t]{2}{*}{ Share Hispanic (county) } & -0.539 & 0.181 & 1.614 \\
\hline & $(0.342)$ & $(0.434)$ & $(1.149)$ \\
\hline \multirow[t]{2}{*}{ Poverty share (county) } & -0.081 & -0.231 & -0.008 \\
\hline & $(0.129)$ & $(0.220)$ & $(0.370)$ \\
\hline \multirow[t]{2}{*}{ MA penetration rate (county) } & $-0.001^{c}$ & -0.001 & $-0.003^{\mathrm{b}}$ \\
\hline & $(0.001)$ & $(0.001)$ & $(0.001)$ \\
\hline \multirow[t]{2}{*}{ Emp.-pop. ratio (county) } & 0.011 & 0.002 & 0.023 \\
\hline & $(0.023)$ & $(0.042)$ & $(0.086)$ \\
\hline Dependent mean & 0.314 & 0.775 & 3.252 \\
\hline $\begin{array}{l}\% \text { change in HPRD for a } 5 \% \text { increase } \\
\text { in the Medicare payment rate }\end{array}$ & 9.01 & 3.24 & 0.81 \\
\hline
\end{tabular}


TABLE 3. Continued

\begin{tabular}{lccc}
\hline & RN HPRD & LPN HPRD & DC HPRD \\
& (1) & (2) & (3) \\
\hline Number of facilities & 13,203 & 13,203 & 13,202 \\
Number of observations & 76,862 & 76,835 & 76,696 \\
\hline
\end{tabular}

Note: The table reports the results from estimating equation 5. For covariates, each cell reports the coefficient estimate and the robust standard error of the estimate clustered by unique MSACBSA pairings (in parentheses). All models also include facility fixed effects, year fixed effects, stateby-year fixed effects, and a set of interaction terms between year indicator variables and the county's urban share. Observations are weighted by facility number of Medicare/Medicaid certified beds. The percentage change in HPRD is interpreted for a standard increase in the Medicare payment rate, which is defined as a $5 \%$ rise in Medicare payment for facilities with a Medicare share of $10 \%$

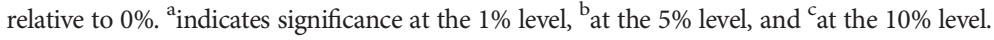

from the geographic realignment. Online Appendix Figure A1; examines this in more detail by plotting mean RN, LPN, and DC HPRD over time and by quartiles in Medicare share. The differential trends shown in the figure are consistent with the regression results. For example, average RN and DC HRPD increased over time for facilities in quartiles 1 through 3 of the Medicare share distribution, but fell for facilities in the top quartile of Medicare share. For LPN HPRD, average hours rose for facilities in all quartiles, but rose to a lesser extent for facilities in the top quartile of the Medicare share distribution. The large coefficient estimates for the POST $\times$ Medicare share interaction are not a threat to identification, since our identifying variation comes from plausibly exogenous geographybased payment changes, rather than Medicare intensity alone.

Because staffing is measured in terms of hours per resident day, we check whether the staffing results in Table 3 are simply driven by changes in resident days. That is, if payment increases had reduced volume, this would have mechanically increased hours per resident day. Although such an effect is counter to the traditional supply-side response of profitmaximizing firms, it could occur if facilities engage in demand inducement when Medicare payments fall. As a check, we estimate equation 5 where the dependent variable is the log of total resident days. Table 4 reports the results; the estimated coefficient is small and statistically insignificant. Thus, changes in resident days do not explain the observed changes in staffing hours per resident day.

\section{B. EVENT STUDY SPECIFICATIONS}

We next report the results from an event study specification in which we allow the effect of the payment change interacted with Medicare share to vary by year. This allows us to test the key identifying assumption in our models, which is that in the absence of the HWI-induced payment changes, the unobserved differences in staffing between facilities that experienced payment changes and those that did not would be the same over time, among high Medicare share facilities relative to low share ones. For this specification, we replace the interaction term $\triangle$ Payment $_{i} \times$ POST $_{t} \times$ Medicare Share $_{i}$ in equation 5 with a series of interaction terms between a dummy variable for each year of our sample and 
TABLE 4. Effect of payment changes on resident days

\begin{tabular}{lc}
\hline & Log (total resident days) \\
\hline$\Delta$ Payment $\times$ Post $\times$ Medicare Share & -0.636 \\
Number of facilities & $(1.029)$ \\
Number of observations & 12,403 \\
\hline
\end{tabular}

Note: The table reports the results from estimating a variation of equation 5 in which the dependent variable is the log of total resident days, instead of a measure of staffing. For brevity we report only the key coefficient estimate from the model and its robust standard error clustered by unique MSA-CBSA pairings (in parentheses). The model also includes the full list of covariates reported in Table 3, plus facility fixed effects, year fixed effects, state-by-year fixed effects, and a set of interaction terms between year indicator variables and the county's urban share. Observations are weighted by facility number of Medicare/Medicaid certified beds.

$\Delta$ Payment $_{i} \times$ Medicare Share $_{i}$. We omit the interaction term for 2005, the year before the geographic change, as the base year. We also include the 2006 data and allow the model to test directly for differential effects across the transition year and other post-change years.

We plot the estimated interaction term coefficients from these specifications in Figure 4, and the results are supportive of the causal effects we report in Table 3. We test for support of the parallel trend assumption by looking at the coefficient estimates for the interaction of $\Delta$ Payment and Medicare Share in the pre-period. The small point estimates for 2004 and 2005 suggest that there were not significant differential staffing pretrends between positive Medicare share facilities experiencing payment changes and zero Medicare share facilities experiencing payment changes. Further, increases in Medicare payment interacted with Medicare share had significant positive effects on RN and LPN hours per resident day in the post period $(p<0.10)$.

\section{ROBUSTNESS TESTS}

As noted above, the geographic change we study affected Medicare payments to hospitals too, because the HWI is also used to adjust hospital payments up or down by differences in labor costs across areas. Although the results from Shin (2019) showed no evidence that hospital admissions, length of stay, or readmissions were affected by the HWI change, we might be concerned that the payment change led to some other change in hospital behavior that could have implications for post-acute care in SNFs, and thus for facility staffing levels. To address this concern, we constructed a measure of the average hospital HWI change between 2004 and 2008 across hospitals located in each SNF's hospital service area and controlled for that measure. Specifically, we added two interaction terms to our explanatory variables in equation 5: (1) the change in the area average hospital HWI multiplied by POST and Medicare share, and (2) the change in the area average hospital HWI multiplied by POST. ${ }^{18}$ The results are reported in Table 5 . The coefficients on the additional

18 We use CMS Hospital Impact Files to construct this measure. For each hospital, the change in HWI is measured as the post-reclassification HWI in 2008 minus the post-reclassification HWI in 2004. We average HWI changes for hospitals located in the same hospital service area (HSA), weighting by hospital beds, and 
interaction terms are not statistically significant in any of three staffing models, while the coefficients on our key explanatory variable, the facility-specific payment change interacted with POST and Medicare share, are largely unchanged. Here, the simulated effects of a five percent payment increase (for 10 percent relative to 0 percent Medicare share facilities) are statistically significant, implying 8.16 percent and 3.44 percent increases in RN HPRD and LPN HPRD, respectively.

Our main estimates are also robust to other changes in the controls (results available upon request). Compared with the results shown in Table 3, the effect sizes are somewhat larger when we exclude all time-varying facility controls (nonprofit ownership, being part of a chain, number of beds) from the models. Here, simulated effects of a 5 percent payment increase (for 10 percent relative to 0 percent Medicare share facilities) are a 9.4 percent rise in RN HPRD and a 3.54 percent rise in LPN HPRD (both statistically significant). Estimates change by very little when we add interaction terms between each of the year indicator variables and a metro area indicator for the county, instead of county urban share. We estimate slightly smaller effect sizes when we exclude state-by-year dummy variables from the set of controls, given concerns of overfitting the model by including the large set of state-by-year dummies. Here, simulated effects of a 5 percent payment increase (for 10 percent relative to 0 percent Medicare share facilities) are an 8.78 percent rise in $\mathrm{RN}$ HPRD and a 3.06 percent rise in LPN HPRD (both statistically significant).

Our identification strategy exploits differences in facility exposure to Medicare share in the period prior to the payment change; this approach may produce biased estimates if facilities with higher Medicare shares make staffing adjustments differently from facilities with lower Medicare share. For example, some high Medicare share facilities may specialize in rehabilitation services and as a result may have different staffing needs. We address this concern in three ways. First, our main analysis deals with this indirectly by excluding in-hospital SNFs from the estimation sample because those SNFs treat a disproportionately large share of Medicare patients. The mean Medicare share in in-hospital SNFs is 32.3 percent, more than twice as large as our sample average of 14.5 percent; for one-quarter of in-hospital SNFs, the Medicare share is 80 percent or more, compared with only 0.5 percent of SNFs in our sample. ${ }^{19}$

Second, we estimate our main specification (equation 5) using a sample that excludes facilities with Medicare shares greater than or equal to 70 percent. The results are reported in Table 6, and are very similar to the main sample results. The bottom row shows that the same large simulated payment increase led $\mathrm{RN}$ hours per resident day to increase by 7.02 percent and LPN hours per resident day to increase by 4.02 percent, compared with 9.01 percent and 3.24 percent (respectively) in the full sample.

merge the average changes to each nursing facility in our sample by the facility HSA. The HSA is a unit of geography used in the Dartmouth Atlas Project. It reflects local markets for hospital care. We use the 2008 post-reclassification HWI since a large share of hospitals petition or receive adjustments to their HWI values between 2004 and 2007. We note that for a number of SNFs in our data set, we were unable to construct this measure because of missing data in the Impact Files. SNFs to which we were unable to assign a hospital HWI change are located predominantly in small areas, which is consistent with the fact that Critical Access Hospitals are exempted from PPS payment.

19 Descriptive statistics pertain to the sample of SNFs in 2005. 
AMERICAN JOURNAL OF HEALTH ECONOMICS
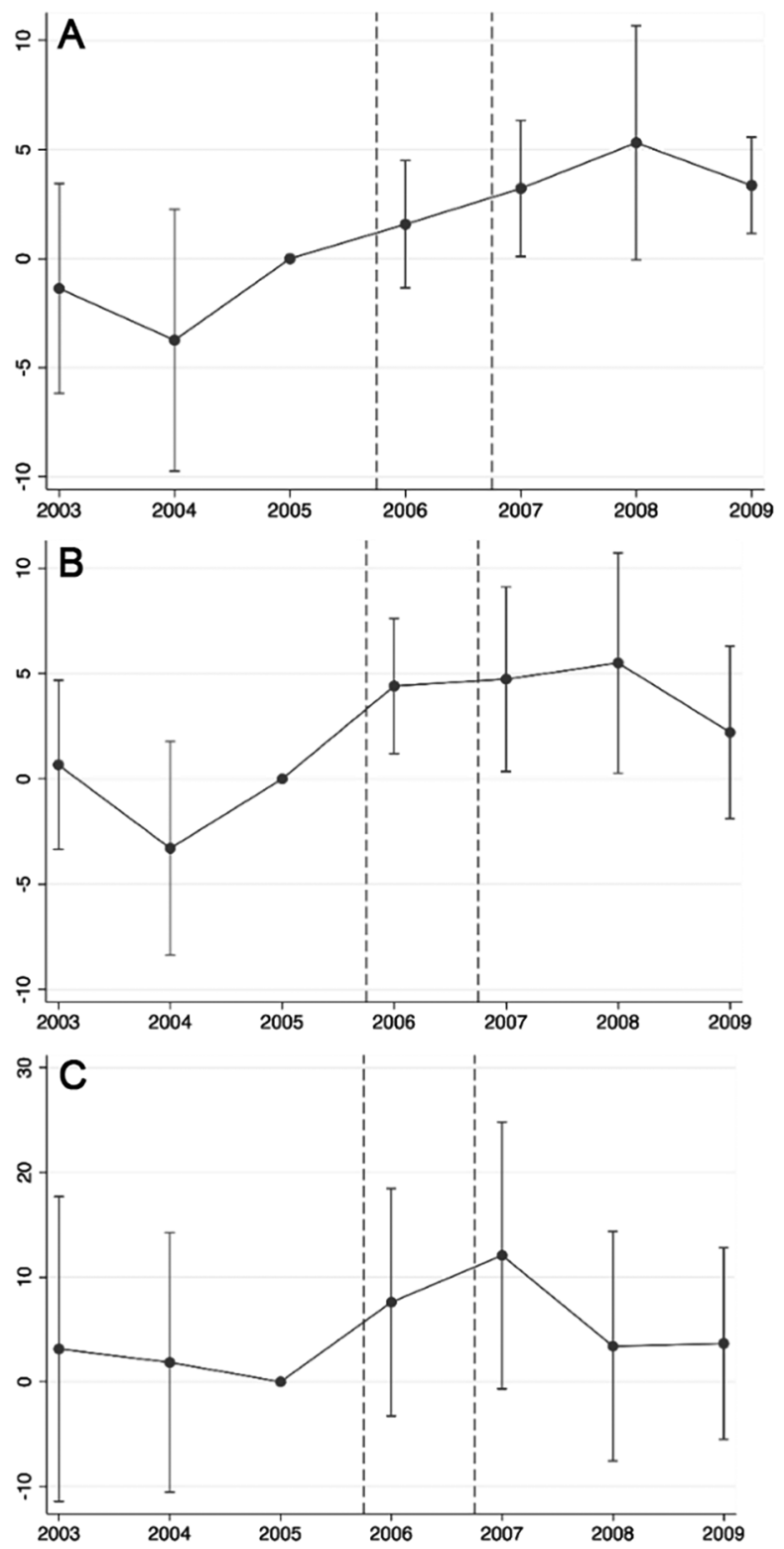

FIGURE 4. Effects of payment changes on nurse HPRD by year. The points plotted in the figures are the estimated coefficients of the interaction of $\Delta$ Payment $\times$ Medicare Share with individual year dummy variables for each year in our sample. We omit an interaction term for 2005, the year prior to the payment change. The brackets show the $90 \%$ confidence interval for the point estimate. The dashed drop lines indicate the start and end of the transitional year before the CBSA-based HWI was fully implemented. A: Dependent variable is RN HPRD. B: Dependent variable is LPN HPRD. C: Dependent variable is DC HPRD. A color version of this figure is available online. 
TABLE 5. Effects of facility payment changes on staffing, controlling for area average hospital payment changes

\begin{tabular}{lccc}
\hline & $\begin{array}{c}\text { RN HPRD } \\
\text { (1) }\end{array}$ & $\begin{array}{c}\text { LPN HPRD } \\
\text { (2) }\end{array}$ & $\begin{array}{c}\text { DC HPRD } \\
\text { (3) }\end{array}$ \\
\hline$\Delta$ Payment $\times$ Post $\times$ Medicare Share & $5.206^{\mathrm{a}}$ & $5.422^{\mathrm{b}}$ & 4.905 \\
& $(2.006)$ & $(2.150)$ & $(5.899)$ \\
& -0.610 & 0.549 & 0.369 \\
$\Delta$ Area Hospital HWI $\times$ Post $\times$ Medicare Share & $(0.380)$ & $(0.441)$ & $(1.471)$ \\
$\Delta$ Area Hospital HWI $\times$ Post & 0.271 & -0.357 & -0.362 \\
& $(0.198)$ & $(0.221)$ & $(0.730)$ \\
\% change in HPRD for a 5\% increase in the & & & \\
$\quad$ Medicare payment rate & 8.16 & 3.44 & 0.75 \\
$N$ & 66,203 & 66,175 & 66,055 \\
\hline
\end{tabular}

Note: The table reports the results from estimating a variation of equation 5 in which two additional controls are added: the interaction of the change in the area average hospital wage index with POST and the triple interaction of the change in the area average hospital wage index, POST, and Medicare share. We report coefficient estimates from the model and the robust standard errors of the estimates clustered by unique MSA-CBSA pairings (in parentheses). All models also include the full list of covariates reported in Table 3, plus facility fixed effects, year fixed effects, state-by-year fixed effects, and a set of interaction terms between year indicator variables and the county's urban share. Observations are weighted by facility number of Medicare/Medicaid certified beds. The percentage change in HPRD is interpreted for a standard increase in the Medicare payment rate, which is defined as a $5 \%$ rise in Medicare payment for facilities with a Medicare share of $10 \%$ relative to $0 \%{ }^{a}$ indicates significance at the $1 \%$ level, ${ }^{b}$ at the $5 \%$ level, and ${ }^{c}$ at the $10 \%$ level.

Third, we report the results from estimating equation 6 below for subgroups of facilities with similar Medicare shares:

$$
y_{i t}=\gamma \Delta \text { Payment }_{i} \times \text { POST }_{t}+\beta_{1} X_{i t}+\gamma_{i}+\tau_{t}+\lambda_{s t}+\varepsilon_{i t}
$$

In this equation, identification of payment changes comes from comparing changes in facility staffing before and after the payment change across facilities with different size payment changes, and the estimated coefficient on the double interaction term gives the effect of the payment change. Note that this model does not rely on the variation in Medicare share for identification. Instead, we estimate this model for three subgroups of facilities defined by tercile in Medicare share. The results are reported in the first three panels of Table 7. For comparison, the fourth panel contains the full sample results; Online Appendix Table A1; reports the full model results for the full sample. Results from the RN HPRD models lack the necessary precision to show a clear relationship, but they suggest that effects vary by Medicare share. In contrast, we find that the simulated large payment increase led to comparably sized 3.2 to 4.3 percent increases in LPN HPRD in facilities with high, middle, and low shares of Medicare patients. The effects are statistically significant for facilities in the middle and top terciles. We then estimate analogous event study specifications. 
TABLE 6. Effects of payment changes on staffing, excluding SNFs with Medicare share $>70 \%$

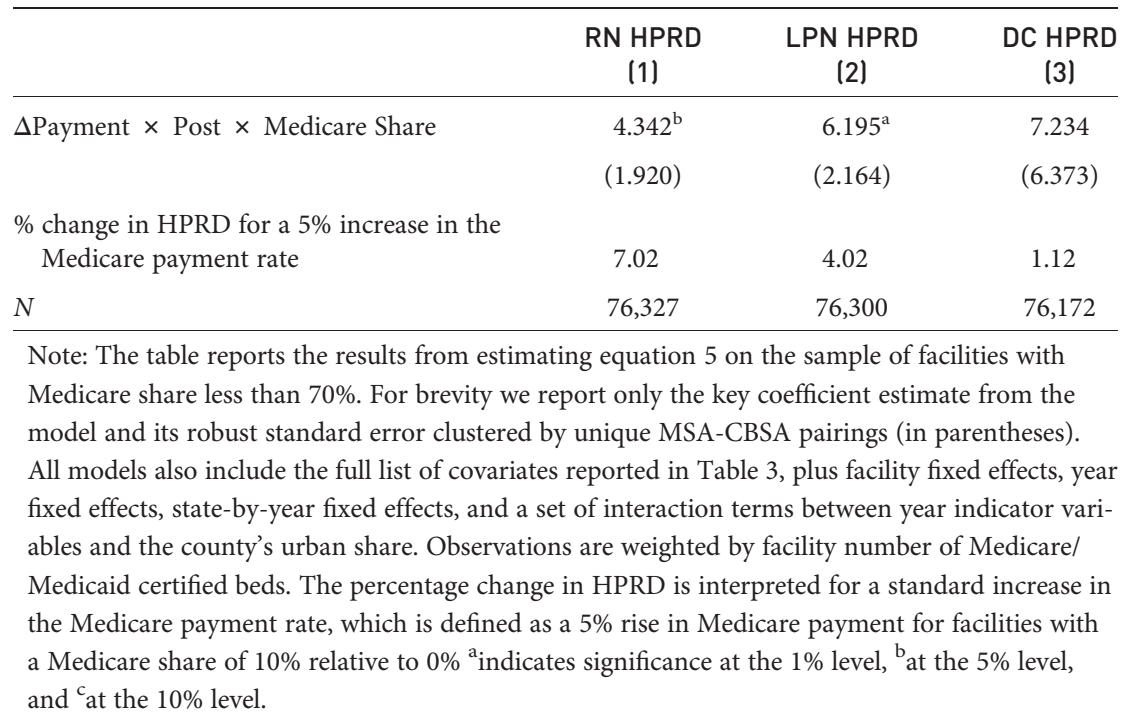

The results are reported in Online Appendix Figures A2-A5;. While the confidence intervals are large in these specifications, we find little evidence of differential staffing trends by Medicare payment change prior to 2005. Online Appendix Figures A2B and A3B; show that payment increases raised LPN HPRD in high and medium Medicare share facilities. The increase appears to remain throughout our sample period (through 2009) in high Medicare share facilities but dissipates beginning in 2008 for medium Medicare share facilities. One drawback of this alternative identification strategy is that the policy variation is exclusively location based and does not use the variation resulting from the differential exposure across facilities.

\section{ADDITIONAL ANALYSIS}

As shown in Table 1, the geographic realignment led to payment increases and decreases of varying sizes. In this section, we examine whether staffing responses varied by the direction and size of the payment change. We test for asymmetric and nonlinear responses to payment changes by estimating equation 7 :

$$
\begin{aligned}
& y_{i t}=\alpha_{1} \text { Large Increase }_{i} \times \text { POST }_{t} \times \text { Medicare Share }_{i}+\alpha_{2} \text { Small Increase }_{i} \times \text { POST }_{i} \\
& \times \text { Medicare Share }_{i}+\alpha_{3} \text { Small Decrease }_{i} \times \text { POST }_{t} \times \text { Medicare Share }_{i} \\
& +\alpha_{4} \text { Large Decrease }_{i} \times \text { POST }_{t} \times \text { Medicare Share }_{i}+\alpha_{5} \text { Large Increase }_{i}
\end{aligned}
$$

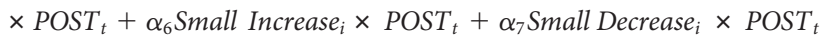

$$
\begin{aligned}
& +\alpha_{8} \text { Large Decrease }_{i} \times \text { POST }_{t}+\alpha_{9} \text { POST }_{t} \times \text { Medicare Share }_{i}+\beta_{1} X_{i t}+\gamma_{i}+\tau_{t}+\lambda_{s t}+\varepsilon_{i t}
\end{aligned}
$$


TABLE 7. Effects of payment changes on staffing, double interaction specification results by Medicare share

\begin{tabular}{|c|c|c|c|}
\hline & $\begin{array}{l}\text { RN HPRD } \\
\text { (1) }\end{array}$ & $\begin{array}{c}\text { LPN HPRD } \\
\text { (2) }\end{array}$ & $\begin{array}{c}\text { DC HPRD } \\
\text { (3) }\end{array}$ \\
\hline \multicolumn{4}{|c|}{ A. SNFs in top tercile of Medicare share } \\
\hline \multirow[t]{2}{*}{$\Delta$ Payment $\times$ Post } & 0.244 & $0.742^{\mathrm{b}}$ & 0.439 \\
\hline & $(0.290)$ & $(0.304)$ & $(0.567)$ \\
\hline \multicolumn{4}{|c|}{$\%$ change in HPRD for a $5 \%$ increase in the } \\
\hline Medicare payment rate & 3.22 & 4.28 & 0.63 \\
\hline$N$ & 25,823 & 25,797 & 25,716 \\
\hline \multicolumn{4}{|c|}{ B. SNFs in middle tercile of Medicare share } \\
\hline \multirow[t]{2}{*}{$\Delta$ Payment $\times$ Post } & 0.085 & $0.518^{\mathrm{c}}$ & 0.571 \\
\hline & $(0.260)$ & $(0.276)$ & $(0.807)$ \\
\hline \multicolumn{4}{|c|}{$\%$ change in HPRD for a $5 \%$ increase in the } \\
\hline Medicare payment rate & 1.52 & 3.39 & 0.90 \\
\hline$N$ & 26,065 & 26,059 & 26,036 \\
\hline \multicolumn{4}{|c|}{ C. SNFs in bottom tercile of Medicare share } \\
\hline \multirow[t]{2}{*}{$\Delta$ Payment $\times$ Post } & -0.278 & 0.449 & -0.184 \\
\hline & $(0.235)$ & $(0.365)$ & $(0.577)$ \\
\hline \multicolumn{4}{|c|}{$\%$ change in HPRD for a $5 \%$ increase in the } \\
\hline Medicare payment rate & -4.91 & 3.23 & -0.29 \\
\hline$N$ & 24,974 & 24,979 & 24,944 \\
\hline \multicolumn{4}{|c|}{ D. Double interaction specification: Full sample } \\
\hline \multirow[t]{2}{*}{$\Delta$ Payment $\times$ Post } & 0.090 & $0.565^{\mathrm{a}}$ & 0.402 \\
\hline & $(0.193)$ & $(0.198)$ & $(0.379)$ \\
\hline \multicolumn{4}{|c|}{$\%$ change in HPRD for a $5 \%$ increase in the } \\
\hline Medicare payment rate & 1.43 & 3.64 & 0.62 \\
\hline$N$ & 76,862 & 76,835 & 76,696 \\
\hline
\end{tabular}

Note: The table reports the results from estimating equation 6 . For covariates, each cell reports the coefficient estimate and the robust standard error of the estimate clustered by unique MSACBSA pairings (in parentheses). All models also include facility fixed effects, year fixed effects, state-by-year fixed effects, and a set of interaction terms between year indicator variables and the county's urban share. Observations are weighted by facility number of Medicare/Medicaid certified beds. The percentage change in HPRD is interpreted for a standard increase in the Medicare payment rate, which is defined as a $5 \%$ rise in Medicare payment for facilities with a Medicare share of $10 \%$ relative to $0 \%$. ${ }^{a}$ indicates significance at the $1 \%$ level, ${ }^{b}$ at the $5 \%$ level, and ${ }^{c}$ at the $10 \%$ level. 


\section{AMERICAN JOURNAL OF HEALTH ECONOMICS}

This specification replaces the continuous measure of payment change from equation 5 with a set of four indicator variables for whether the facility experienced a large payment increase, small payment increase, small payment decrease, or large payment decrease, with zero change being the omitted category. We define large payment changes as those that are greater than or equal to 1 percent in absolute value, and small changes as less than 1 percent in absolute value. The results are reported in Table 8 . The signs of the estimated coefficients suggest that payment increases usually raise staffing while payment decreases usually reduce staffing, and there is evidence that both large and small payment changes matter. In the RN models, we are not able to reject the null hypothesis that the coefficient of the payment increase term is equal to that of the payment decrease term, for both small and large decreases. Thus the effect seems to be symmetric for payment increases and decreases. However, for LPN and DC models, the evidence is mixed. This exercise may underscore the limited statistical power of our analysis when we cut the data too thinly.

Finally, we examine whether Medicare payment increases are associated with changes in other measures of quality. To examine this, we estimate equation 5 using several annual

TABLE 8. Tests for nonlinear asymmetric effects of payment changes on staffing

\begin{tabular}{lccc}
\hline & RN HPRD LPN HPRD DC HPRD \\
& (1) & (2) & (3) \\
\hline Large $(1 \%+)$ payment increases $\times$ Post $\times$ Medicare Share & $0.339^{\mathrm{a}}$ & $0.502^{\mathrm{a}}$ & 0.217 \\
& $(0.102)$ & $(0.161)$ & $(0.338)$ \\
Small $(0 \%-1 \%)$ payment increases $\times$ Post $\times$ Medicare Share & $0.281^{\mathrm{c}}$ & 0.133 & -0.339 \\
& $(0.168)$ & $(0.203)$ & $(0.260)$ \\
Small $(0 \%-1 \%)$ payment decreases $\times$ Post $\times$ Medicare Share & $-0.366^{\mathrm{c}}$ & -0.305 & $-0.538^{\mathrm{c}}$ \\
& $(0.199)$ & $(0.222)$ & $(0.290)$ \\
Large $(1 \%+)$ payment decreases $\times$ Post $\times$ Medicare Share & -0.057 & 0.110 & -0.498 \\
$\begin{array}{l}\text { p-value from the hypothesis test that large increases and } \\
\text { decreases have an equal-sized effect }\end{array}$ & $(0.171)$ & $(0.160)$ & $(0.328)$ \\
$\begin{array}{l}\text {-value from the hypothesis test that small increases and } \\
\text { decreases have the same effect }\end{array}$ & 0.238 & 0.037 & 0.579 \\
$\begin{array}{l}\text { Number of facilities } \\
\text { Number of observations }\end{array}$ & 0.770 & 0.629 & 0.039 \\
\hline
\end{tabular}

Note: This table reports the results from estimating equation 7 . For covariates, each cell reports the coefficient estimate and the robust standard error of the estimate clustered by unique MSACBSA pairings (in parentheses). All models also include the interactions of large/small payment increases/decreases with POST, the interaction of POST and Medicare share, plus the timevarying facility and county traits shown in Table 3 and facility fixed effects, year fixed effects, and state-by-year fixed effects. ${ }^{a}$ indicates significance at the $1 \%$ level, ${ }^{b}$ at the $5 \%$ level, and ${ }^{c}$ at the $10 \%$ level. 
The Effects of Medicare Payment Changes on Nursing Home Staffing // HE ET AL.

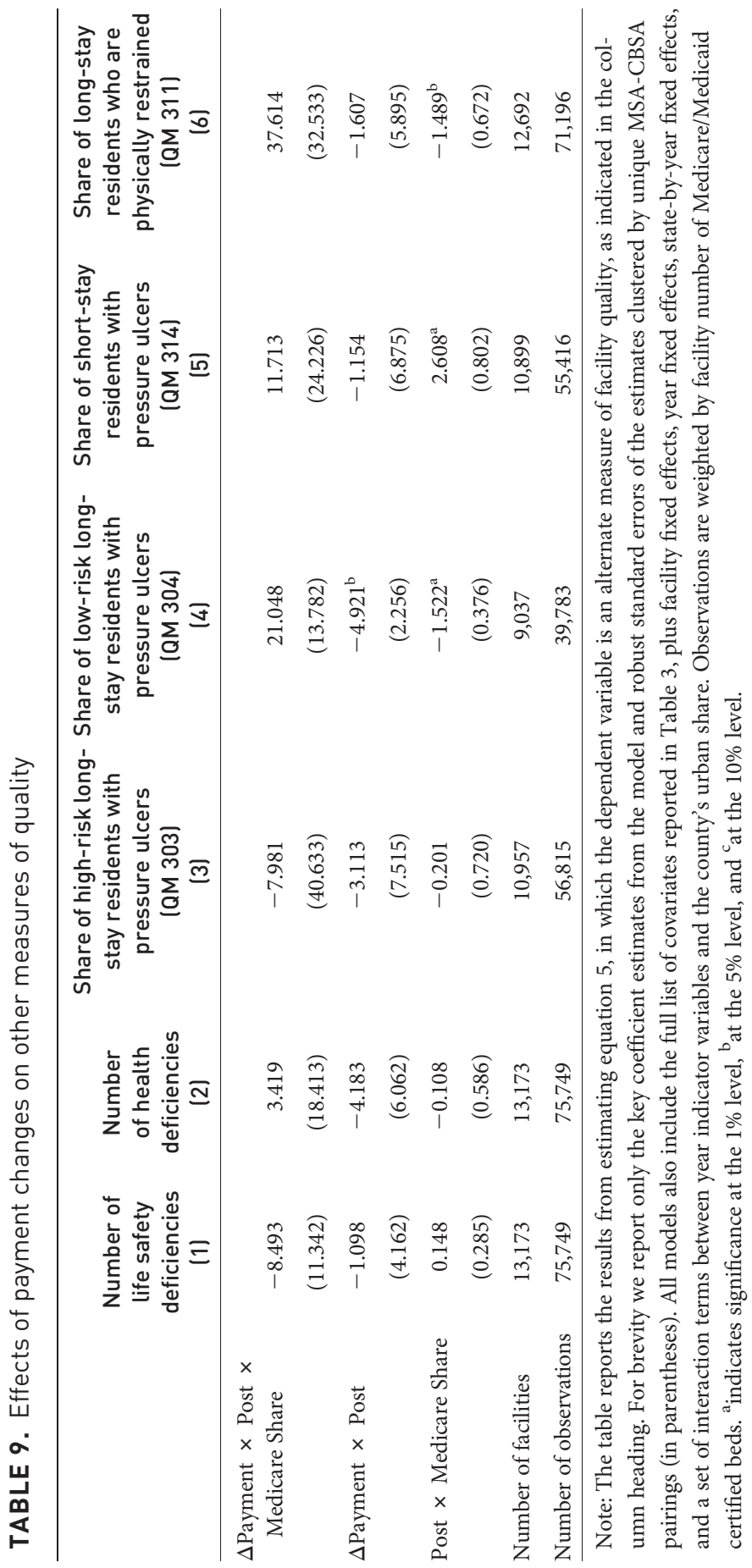




\section{AMERICAN JOURNAL OF HEALTH ECONOMICS}

facility-level measures of quality as dependent variables in separate regressions. Specifically, we model the number of life safety deficiencies, the number of health deficiencies, the percentage of residents with pressure ulcers (among high- and low-risk long-stay residents and short-stay residents), and the percentage of long-stay residents who are physically restrained. The results are reported in Table 9. The coefficient estimates for the main explanatory variable, the triple interaction between change in payment, baseline Medicare share, and the POST indicator, are not statistically significant in any of the models. Admittedly, measures like life safety deficiencies are based on characteristics of the facility's physical plant, which may be slow to change. Further, only one of these additional measures is specific to short-stay residents, so we have limited ability to test whether Medicare payment increases translated to quality improvements specific to Medicare patients. ${ }^{20}$

\section{Conclusions}

We use a novel strategy to identify the causal effects of facility-specific Medicare payment changes on nursing home staffing. We find that increases in Medicare payments led facilities to increase nursing staff hours per resident day. Specifically, RN and LPN hours per resident day increased by 9.01 percent and 3.24 percent respectively in response to a 5 percent rise in Medicare payment, for facilities with 10 percent of resident days paid by Medicare relative to those with zero Medicare patients. Our results are robust to various specification changes, including a flexible event study specification that provides support for our identifying assumption of parallel trends in the pre-period data. The increases in staffing hours per resident day do not arise mechanically from decreases in resident days.

To put our estimates' magnitudes in context, consider the following back-of-the-envelope calculation that connects a hypothetical Medicare payment increase to nurse payroll spending. For this exercise, we consider a 5 percent increase in the Medicare per diem payment rate; given that the average Medicare per diem in our sample in 2005 was $\$ 262$, this amounts to an increase of $\$ 13.10$. Further, we used the Current Population Surveys during our sample period to calculate the mean hourly wages of RNs and LPNs working at nursing homes; these costs are $\$ 22$ and $\$ 17$, respectively. Our main coefficient estimates in Table 3 imply average effects on $\mathrm{RN}$ and $\mathrm{LPN}$ hours per resident day of $0.028(5.665 \times 0.05 \times[0.1-0.0])$ and $0.025(5.023 \times 0.05 \times[0.1-0.0])$, respectively, at facilities with 10 percent Medicare share relative to facilities with zero Medicare share. Multiplying by average wages per hour, those effect estimates imply increased spending on RNs and LPNs of $\$ 0.62$ and $\$ 0.43$ per resident day, respectively. Taking RNs and LPNs together, a SNF with 10 percent Medicare share would spend $\$ 1.05$ more on staffing out of the $\$ 13.10$ reimbursement increase relative to a SNF with zero Medicare share. This suggests that 8 percent of the payment increase is transferred directly to spending on patient care through staffing. Note that our measure of

20 In a robustness check, we also estimated models in which each of the 11 other individual QMs (including two other short-stay measures) served as the dependent variable in a separate regression. In only one case was the coefficient of the main explanatory variable statistically significant (the share of long-stay residents feeling depressed or anxious), and the sign of the coefficient was positive, which runs counter to expectations. The results are available upon request. 
staffing applies to the entire facility, not just nursing staff who deliver care to Medicare patients.

Staffing is a structural measure of quality; we also tested whether payment decreases were associated with a range of measures that represent other measurable dimensions of quality, including process and outcomes of care. We found little evidence that other measures of quality improved as payments rose. In this way, our work is also similar to other papers that have examined the impact of Medicare payment changes on nonstaffing measures of quality. For example, prior studies on the effects of Medicare payment rates on other dimensions of quality have also failed to identify significant changes in facility inspection deficiencies, pressure sores, and restraint use (Konetzka et al. 2004; White 2005). It remains possible that the staffing changes we identified affected unmeasured or unobservable quality dimensions (Werner, Konetzka, and Kruse 2009).

Our study has several limitations. First, although we have a strong identification strategy, we cannot completely rule out the possibility that the HWI shocks to facilities could be endogenous. For example, the shocks are geographically related and could be incidentally correlated with other local changes. We do, however, control for facility fixed effects and urban population share interacted with year dummy variables. In an alternative specification we control for a facility's metro status with year dummy variables, and our results are very similar. Second, we examine a one-time policy shock that occurred in 2005, so one may question the generalizability of our results to the current debate about Medicare payment reform and nursing home quality shortcomings. We acknowledge the lack of external validity, but we note the typical trade-off between external validity and internal validity. Third, our measures of staffing are reported by facilities and prone to measurement error (e.g., Castle 2008). Medicare has only recently begun to release the payroll data that nursing homes are required to report under the ACA (Rau and Lucas 2018); as far as we know, no other facility-level sources of administrative data on staffing are available nationwide. Additionally, the staffing measures we use, as well as some of the other quality measures reported in Table 9, are not specific to Medicare. It is possible that facility responses to Medicare payment changes occur on payer-specific dimensions of quality. Fourth, the studied shock to HWI for most facilities induces a somewhat small impact on Medicare payment. We however note that those seemingly small price shocks may be quite important for the profit margins of nursing homes, and could plausibly lead to important facility responses. Finally, our analysis focuses on staffing responses; another type of facility response to changes in financial incentives is to engage in upcoding (e.g., Bowblis and Brunt 2014). Shin (2019) reports that hospitals engaged in upcoding in response to the same type of payment shock we examine. Whether nursing facilities act similarly is a question for future research.

Our findings have important implications for public policy. Future Medicare payment policy recommendations should carefully consider the evidence that Medicare reimbursement cuts could lead to reduced staffing levels. This is especially important in light of recommended and actual cuts to PPS payment rates. For example, MedPAC has recommended freezing or reducing Medicare payments under the SNF PPS in each of the past 10 years, and in 2010, the ACA authorized $\$ 200$ billion in Medicare payment cuts over 10 years (MedPAC, various years; Congressional Budget Office 2010). Such payment cuts can significantly 


\section{AMERICAN JOURNAL OF HEALTH ECONOMICS}

reduce health-care providers' reimbursements; indeed, CMS estimates that the ACA cuts will result in negative margins for half of all hospitals and two-thirds of skilled nursing facilities by 2040 (Heffler et al. 2016). Our results suggest that such changes, and the important changes under way as the new SNF Value-Based Purchasing Program imposes financial penalties on some facilities and rewards others, could have important and uneven impacts on nursing home resident experiences.

\section{REFERENCES}

Bostick, Jane, Marilyn Rantz, Marcia Flesner, and C. Jo Riggs. 2006. "Systematic Review of Studies of Staffing and Quality in Nursing Homes." Journal of the American Medical Directors Association 7 (6): 366-76. https://doi.org/10.1016/j.jamda.2006.01.024.

Bowblis, John. 2011. "Staffing Ratios and Quality: An Analysis of Minimum Direct Care Staffing Requirements for Nursing Homes.” Health Services Research 46 (5): 1495516. https://doi.org/10.1111/j.1475-6773.2011.01274.x.

Bowblis, John, and Christopher Brunt. 2014. "Medicare Skilled Nursing Facility Reimbursement and Upcoding." Health Economics 23 (7): 821-40. https://doi.org/10.1111/j .1475-6773.2011.01274.x.

Capretta, James, and Joseph Antos. 2015. Indexing in the Affordable Care Act: The Impact on the Federal Budget. Arlington, VA: Mercatus Center at George Mason University. https://www.mercatus.org/system/files/Capretta-Indexing-ACA.pdf.

Castle, Nicholas. 2008. "Nursing Home Caregiver Staffing Levels and Quality of Care: A Literature Review." Journal of Applied Gerontology 27 (4): 375-405. https://doi.org /10.1177/0733464808321596.

Centers for Medicare and Medicaid Services. 2001. Appropriateness of Minimum Nurse Staffing Ratios in Nursing Homes. Report to Congress: Phase II Final. Vols. I-III. Cambridge, MA: Abt Associates.

_. 2016. "Wage Index." https://www.cms.gov/medicare/medicare-fee-for-service -payment/snfpps/wageindex.html.

_ 2018a. "NHE Fact Sheet." https://www.cms.gov/research-statistics-data-and-sys tems/statistics-trends-and-reports/nationalhealthexpenddata/nhe-fact-sheet.html.

_.2018b. "Medicare Issues Fiscal Year 2019 Payment and Policy Changes for Skilled Nursing Facilities.” https://www.cms.gov/newsroom/fact-sheets/medicare-issues-fis cal-year-2019-payment-policy-changes-skilled-nursing-facilities.

_. 2018c. "The Skilled Nursing Facility Value-Based Purchasing Program (SNF VBP).” https://www.cms.gov/Medicare/Quality-Initiatives-Patient-Assessment-In struments/Value-Based-Programs/Other-VBPs/SNF-VBP.html.

Clemens, Jeffery, and Joshua Gottlieb. 2014. "Do Physicians' Financial Incentives Affect Medical Treatment and Patient Health?” American Economic Review 104 (4): 132049. https://doi.org/10.1257/aer.104.4.1320.

Congressional Budget Office. 2010. “Congresssional Budget Office to Nancy Pelosi, March 20, 2010.” https://www.cbo.gov/sites/default/files/111th-congress-2009-2010/costestimate /amendreconprop.pdf. 
Dellefield, Mary, Nickolas Castle, Katherine McGilton, and Karen Spilsbury. 2015. "The Relationship between Registered Nurses and Nursing Home Quality: An Integrative Review (2008-2014).” Nursing Economics 33 (2): 95-108.

Feng, Zhanlian, David Grabowski, Orna Intrator, Jaqueline Zinn, and Vincent Mor. 2008. "Medicaid Payment Rates, Case-Mix Reimbursement, and Nursing Home Staffing: 19962004." Medical Care 46 (1): 33-40. https://doi.org/10.1097/mlr.0b013e3181484197.

Grabowski, David, Zhanlian Feng, Orna Intrator, and Vincent Mor. 2004. "Recent Trends in State Nursing Home Payment Policies.” Health Affairs 23 (Suppl. 1): W4-363-73. https://doi.org/10.1377/hlthaff.w4.363.

Hackmann, Martin. 2019. "Incentivizing Better Quality of Care: The Role of Medicaid and Competition in the Nursing Home Industry." American Economic Review 109 (5): 1684-716. https://doi.org/10.1257/aer.20151057.

Harrington, Charlene, John Schnelle, Margaret McGregor, and Sandra Simons. 2016. "The Need for Higher Minimum Staffing Standards in US Nursing Homes." Health Services Insights 9:13-19. https://dx.doi.org/10.4137\%2FHSI.S38994.

Harrington, Charlene, James Swan, and Helen Carrillo. 2007. "Nurse Staffing Levels and Medicaid Reimbursement Rates in Nursing Facilities." Health Services Research 42 (3 Pt. 1): 1105-29. https:/doi.org/10.1111/j.1475-6773.2006.00641.x.

$\mathrm{He}$, Daifeng, Peter McHenry, and Jennifer Mellor. 2020. "Do Financial Incentives Matter? Effects of Medicare Price Shocks on Skilled Nursing Facility Care." Health Economics 29 (6): 655-70. https://doi.org/10.1002/hec.4009.

Heffler, Steven, Kimberly Andrews, Mary Kate Catlin, and Mollie Knight. 2016. Simulations of Affordable Care Act Medicare Payment Update Provisions on Part A Provider Financial Margins. Wahington, DC: Office of the Actuary, Centers for Medicare and Medicaid Services. Accessed June 17, 2017. https://www.cms.gov/Research-Statistics -Data-and-Systems/Statistics-Trends-and-Reports/ReportsTrustFunds/Downloads /ACAmarginsimulations2016.pdf.

Institute of Medicine (US) Committee on Nursing Home Regulation. 1986. Improving the Quality of Care in Nursing Homes. Washington, DC: National Academy Press.

Institute of Medicine (US) Committee on the Adequacy of Nursing Staff in Hospitals and Nursing Homes. 1996. Nursing Staff in Hospitals and Nursing Homes: Is It Adequate? Washington, DC: National Academy Press.

-2012. Geographic Adjustment in Medicare Payment: Phase I: Improving Accuracy. Washington, DC: National Academy Press.

Intrator, Orna, Jeffrey Hiris, Katherine Berg, Susan Miller, and Vince Mor. 2010. "The Residential History File: Studying Nursing Home Residents' Long-Term Care Histories." Health Services Research 46 (1): 120-37. https://doi.org/10.1111/j.1475-6773.2010 .01194.x.

Kaestner, Robert, and Jose Guardado. 2008. "Medicare Reimbursement, Nurse Staffing, and Patient Outcomes." Journal of Health Economics 27 (2): 339-61. https://doi.org /10.1016/j.jhealeco.2007.04.003.

Kaiser Family Foundation. n.d. "Distribution of Certified Nursing Facility Residents by Payer Source. 2017.” Accessed February 3, 2019. https://www.kff.org/other/state-indi cator/distribution-of-certified-nursing-facilities-by-primary-payer-source/?current 
Timeframe $=0 \&$ sortModel $=\% 7 \mathrm{~B} \% 22$ colId $\% 22: \% 22$ Location $\% 22, \% 22$ sort $\% 22: \% 22$ asc $\% 22 \% 7 \mathrm{D}$.

Konetzka, R. Tamara, Edward Norton, Philip Sloane, Kerry Kilpatrick, and Sally Stearns. 2006. "Medicare Prospective Payment and Quality of Care for Long-Stay Nursing Facility Residents." Medical Care 44 (3): 270-76. https://doi.org/10.1097/01.mlr.00001 99693.82572.19.

Konetzka, R. Tamara, Deokhee Yi, Edward Norton, and Kerry Kilpatrick. 2004. "Effects of Medicare Payment Changes on Nursing Home Staffing and Deficiencies." Health Services Research 39 (3): 463-88. https://doi.org/10.1111/j.1475-6773.2004.00240.x.

Lin, Haizhen. 2014. "Revisiting the Relationship between Nurse Staffing and Quality of Care in Nursing Homes: An Instrumental Variables Approach." Journal of Health Economics 37:13-24. https://doi.org/10.1016/j.jhealeco.2014.04.007.

MaCurdy, Thomas, Thomas Deleire, Karla Lopez de Nava, Paulette Kamenecka, Yang Tan, and Sean McClellan. 2009. Revision of Medicare Wage Index, Final Report, Part 1. Burlingame, CA: Acumen, LLC.

McHenry, Peter, and Jennifer Mellor. 2018. "Medicare Hospital Payment Adjustments and Nursing Wages." International Journal of Health Economics and Management 18 (2): 169-96. https://doi.org/10.1007/s10754-017-9232-x.

Medicare Prospective Payment System and Consolidated Billing for Skilled Nursing Facilities. 2005a. Proposed rule for FY 2006. Federal Register 70 (96): 29070-162 (to be codified as 42 C.F.R. Part 424).

. 2005b. Final rule for FY 2006. Federal Register 70 (146): 45026-127 (to be codified as 42 C.F.R. Parts 409, 411, 424, and 489).

2006. Update-Notice. Federal Register 71 (146): 43158-98.

2007. Final rule for FY 2008. Federal Register 72 (149): 43412-63 (to be codified at 42 C.F.R. Part 409).

MedPAC (Medicare Payment Advisory Commission). Various years. March Report to Congress: Medicare Payment Policy. Washington, DC: MedPAC. http://www.medpac.gov /-documents-/reports.

- 2017. Report to the Congress: Medicare Payment Policy. Washington, DC: MedPAC. http://www.medpac.gov/docs/default-source/reports/mar17_medpac_ch8.pdf ?sfvrsn $=0$.

2018. Skilled Nursing Facility Services Payment System. Washington, DC: MedPAC. http://medpac.gov/docs/default-source/payment-basics/medpac_payment_basics_18 _snf_final_sec.pdf?sfvrsn $=0$.

Mor, Vincent, Cheryl Caswell, Stephen Littlehale, Jane Niemi, and Barry Fogel. 2009. Changes in the Quality of Nursing Homes in the US: A Review and Data Update. Washington, DC: American Health Care Association. https://www.ahcancal.org/research _data/quality/documents/changesinnursinghomequality.pdf.

Rau, Jordan, and Elizabeth Lucas. 2018. "Medicare Slashes Star Ratings for Staffing at 1 in 11 Nursing Homes.” New York Times, July 28, 2018.

Shin, Eunhae. 2019. "Hospital Responses to Price Shocks under the Prospective Payment System." Health Economics 28 (2): 245-60. https://doi.org/10.1002/hec.3839. 
Sloan, Frank. 2000. "Not-for-Profit Ownership and Hospital Behavior." In Handbook of Health Economics, edited by Anthony Culyer and Joseph Newhouse, 1: 1141-74. Philadelphia: Elsevier Science.

US Government Accountability Office. 2018. Nursing Home Quality: Continued Improvements Needed in CMS's Data and Oversight (GAO publication no. GAO-18-694T). Washington, DC: US Government Accountability Office.

US Department of Health and Human Services Office of Inspector General. 2014. Adverse Events in Skilled Nursing Facilities: National Incidence among Medicare Beneficiaries. OEI-06-11-00370. Washington, DC: Department of Health and Human Services.

Werner, Rachel, R. Tamara Konetzka, and Gregory Kruse. 2009. "The Impact of Public Reporting on Unreported Quality of Care.” Health Services Research 44 (2 Pt. 1): 37998. https://dx.doi.org/10.1111\%2Fj.1475-6773.2008.00915.x.

White, Chapin. 2005. "Medicare's Prospective Payment System for Skilled Nursing Facilities: Effects on Staffing and Quality of Care." Inquiry 42 (4): 351-66. https://doi.org /10.5034/inquiryjrnl_42.4.351.

Zinn, Jacqueline, Zhanlian Feng, Vincent Mor, Orna Intrator, and David Grabowski. 2008. "Restructuring in Response to Case Mix Reimbursement in Nursing Homes: A Contingency Approach." Health Care Management Review 33 (2): 113-23. https://doi .org/10.1097/01.hmr.0000304506.12556.52. 